\title{
Collective Action and the Financing of Innovation: Evidence from Crowdfunding
}

\author{
A DISSERTATION \\ Submitted to the Faculty of the Darden Graduate School of Business \\ AT THE UNIVERSITY OF VIRGINIA \\ BY
}

Sean D. Carr

In PARTIAL Fulfillment of the REQUiREMENTS FOR THE DEGREE OF

DOCTOR OF PHILOSOPHY

May 2013

Melissa Thomas-Hunt

Gregory B. Fairchild

Eileen Y. Chou 


\begin{abstract}
Society has a vital interest in encouraging and rewarding innovation and creativity. Neoclassical economic theory suggests that private investors support the funding of innovation in exchange for the opportunity to appropriate financial returns. However, when expected returns are insufficient to motivate investment, market failures may occur and innovation can languish. The recent success of crowdfunding, whereby individuals act collectively to support innovative and entrepreneurial activities despite the absence of conventional incentives, suggests an alternate model for addressing this critical market failure. Given the importance and urgency of this problem, this dissertation explores the following question: Under what conditions and through what mechanisms do voluntary contributors freely support private enterprise in the absence of financial incentives?

Drawing from theories about collective action and the provision of public goods, this thesis advances a hybrid "private investment-collective action" model for the financing of innovation. Second, it integrates the economic and organizational literature with in-depth fieldwork from fifteen crowdfunded ventures to offer a more grounded, socially embedded explanation about the private-collective model in the context of crowdfunding. Finally, because qualitative research may overstate theoretical mechanisms, this work complements the field interviews with a quantitative study of 71,304 crowdfunding campaigns. Furthermore, to establish the internal validity of the
\end{abstract}


main results, I supplement the analysis with a detailed review of 1,316 technology-based crowdfunded projects from within the main dataset; and, to assess the external validity of the findings I conduct a replication of the main analysis with data from an additional 22,548 crowdfunding campaigns collected from an alternative source. This dissertation advances our academic understanding of the social influences on the decision-making behaviors of collective actors in the context of innovation and entrepreneurial finance. The results may be of practical interest to policymakers, educators, investors, entrepreneurs, and innovators.

Keywords: innovation, entrepreneurship, collective action, entrepreneurial finance 
(C) Sean D. Carr 2013 


\section{ACKNOWLEDGMENTS}

Since all scholarship is collaborative, I would like to acknowledge a number of very special people who made it possible to bring this work to fruition.

First and foremost I wish to thank the members of my dissertation committee: Melissa Thomas-Hunt, Greg Fairchild, and Eileen Chou. Their dedication, patience and forbearance during the ups (of which there were many) and downs (only a few) of this process were fundamental to its success. I am forever indebted to their commitment to this work, and I can only hope that I live up to the models of scholarly inquiry that they have set for me. Likewise, I was nurtured in my intellectual development by many other members of the Darden and University of Virginia faculty, especially Saras Sarasvathy, Jim Clawson, Alec Horniman, Erika Hayes, and Jared Harris. In particular I would like to thank Bob Bruner whose insight, ideas, and moral support were invaluable.

I am also grateful to my many dear colleagues at Darden's Batten Institute for Entrepreneurship and Innovation for enabling me to see this through to the end. Among them I must single out the leadership of the Institute. First, I would like to thank Jeanne Liedtka and Elizabeth O’Halloran, former executive director and managing director, respectively, who first gave me the idea and encouragement to enter Darden's Doctoral Program while still keeping me gainfully employed with my work at the Institute; they both showed me that this was an achievable goal and feasible as a full-time employee. At the other end of my tenure in the program, I am grateful to Michael Lenox, Batten's current executive director, for giving me the time and flexibility to finish the program and 
to complete my dissertation amid my other responsibilities. I cannot thank enough all my wonderful colleagues here at Batten, who supported me in more ways than they can ever know. I especially thank Gayle Noble, Debbie White, Philippe Sommer, and my coconspirators in research, Andrew King, Gosia Glinska, Dan Bierenbaum and Susanne Ebling, who showed great patience and understanding at those times when my doctoral research had me pre-occupied or distracted (often both). Of course, I am very thankful for the financial support of the Batten Institute for my participation in the doctoral program and for underwriting my research.

There are also many other people in the Darden community who helped to see me through the doctoral program. I would especially like to acknowledge the support of Pat Werhane, Andy Wicks, Karen Musselman, Linda Buttner, and Kitty Smiley. In addition, I would like to offer thanks to the staff of the Darden library, especially Karen King, as well as the able research assistance provided to me in the final weeks of this project by Marshall Hanbury, Jr., and Tony Douglas.

Financial support was provided by Darden's Research and Course Development Committee, under the leadership of Raj Venkatesan, which provided underwriting for the Kickstarter and indiegogo data collection. I also wish to acknowledge the support of the Ewing Marion Kauffman Foundation, which recognized the proposal for this dissertation through its Emerging Scholars Program in 2012. Also, I am thankful for the fruitful conversations and generous access to sources and data from Korstiaan Zandvliet at Symbid.com and from Carl Esposti and Kevin Berg-Grell at crowdsourcing.org. 
Finally, there are not words to express my gratitude to my wife, Ladislava, for being my always-constant partner in this endeavor. More than once she kept me going and kept the home fires burning while we met this challenge together. And, for my son, Sebastian, thank you for reminding me very day what really matters most in life. 


\section{DEDICATION}

Dedicated to the Memory of

Joseph J. Carr

$(1942-2004)$ 


\section{TABLE OF CONTENTS}

1 Innovation, New Venture Finance, and Crowdfunding.................................

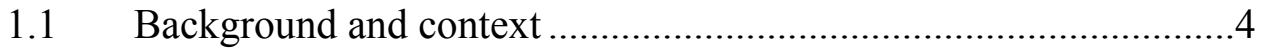

1.2 Conceptualizing crowdfunding ..............................................6

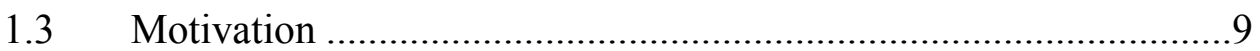

$1.4 \quad$ Potential contributions .......................................................... 11

1.5 Organization ..................................................................... 11

2 Private-Collective Innovation Model: Revisited ...........................................12

2.1 Private-collective innovation model........................................12

2.2 Crowdfunding as a response to market failure ............................15

$2.3 \quad$ Selective incentives ............................................................. 17

$2.4 \quad$ Social engagement ...............................................................20

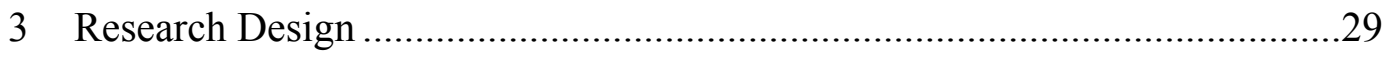

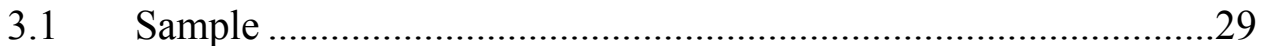

3.2 Dependent variable: Funding outcomes ..................................31

3.3 Independent variable: Selective incentives...............................32

3.4 Independent variable: Social engagement ................................32

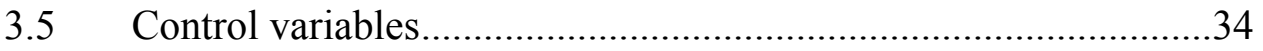

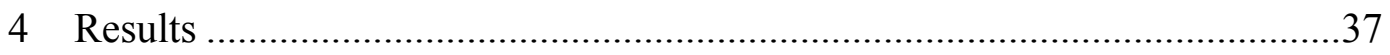

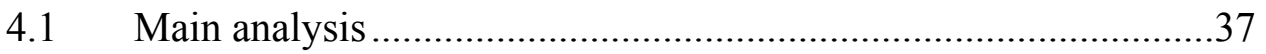

Replication with linear regression ................................................... 39

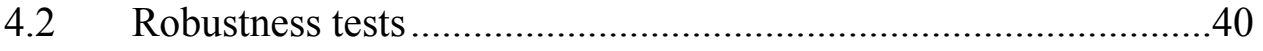

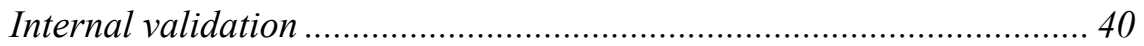

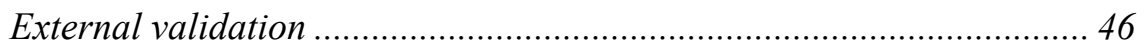




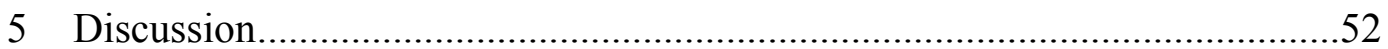

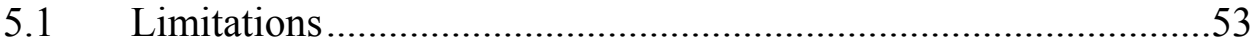

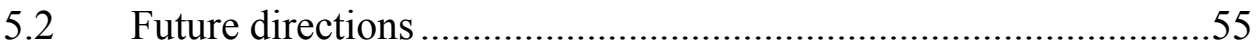

Performance outcomes ……………………………………………........ 55

Geographic patterns ………………………………………………. 57

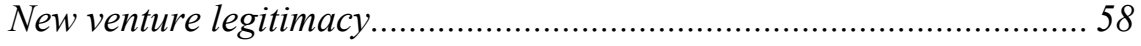

Social information effects ..................................................................... 59

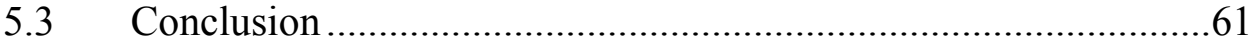

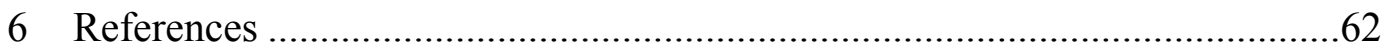

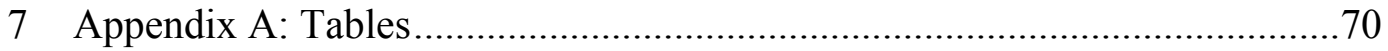

7.1 Summary of campaign characteristics ............................................

7.2 Descriptive statistics and correlations: main analysis .....................71

7.3 Logistic regression: main analysis.................................................72

7.4 Linear regression: main analysis ..................................................

7.5 Descriptive statistics and correlations: internal validation .............74

7.6 Logistic regression: internal validation ...........................................75

7.7 Linear regression: internal validation ...........................................76

7.8 Descriptive statistics and correlations: external validation ............77

7.9 Logistic regression: external validation..........................................78

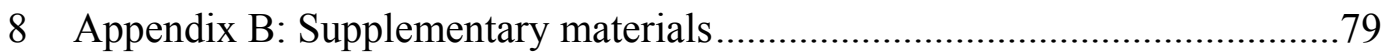

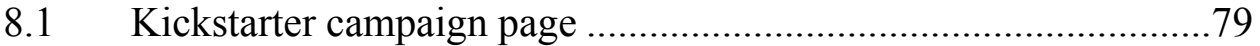

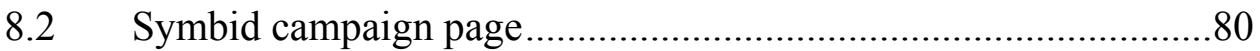

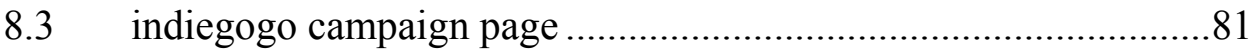

$8.4 \quad$ Kickstarter data: impact on independent film.................................82

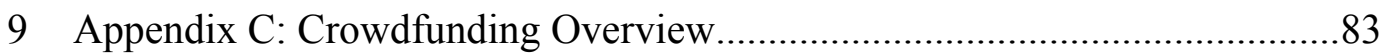

9.1 Crowdfunding defined ................................................................... 
9.2 Antecedents: crowdsourcing and microfinance..........................83

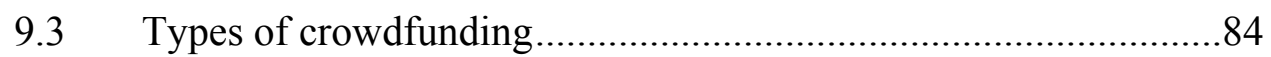

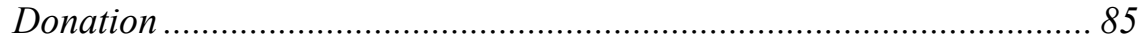

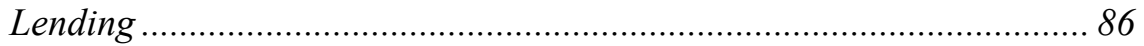

Equity 86

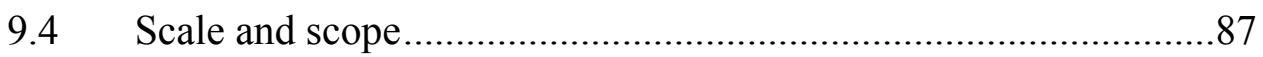




\section{InNOVATION, NEW VENTURE FinANCE, AND CROWDFUNDING}

The poster child of crowdfunding, when a company raises money from multiple individuals online, is a start-up called Pebble Technology Corp. operating out of a cramped, split-level condo. The company is now racing to prove that it and the crowdfunding wave aren't flashes in the pan. Pebble, which is developing a "smart" wristwatch that connects to Apple Inc. iPhones or Google Inc. 's Android phones, in April turned to crowdfunding website Kickstarter Inc. to raise \$100,000 to build its watch. At the time, Pebble was running out of money and badly needed new funding. Within 28 hours of being on Kickstarter, Pebble had raised more than $\$ 1$ million from people who were willing to plunk down $\$ 115$ to pre-order the watch. By midMay, Pebble had snagged a total of \$10.27 million from 68,929 people, making it the most crowdfunded start-up ever in dollar terms, according to Kickstarter and other investors.

The Wall Street Journal 2 July 2012

Financial capital is the fuel that supports innovation and entrepreneurship, yet access to capital remains a significant and persistent problem (Shane, 2003). On the one hand, nascent innovators and entrepreneurs often lack the requisite skills, experience, and sophistication to attract the financial support they need (Cassar, 2004). And, conversely, prospective backers may harbor significant uncertainties about the innovators or entrepreneurs themselves, including concerns about the quality of their innovation or idea, their ability to exploit that idea (Amit, Brander, \& Zott, 1998; Cumming, 2006), and the possibility that they might behave opportunistically with their capital (Williamson, 1993). Since entrepreneurs are typically better informed and more optimistic about their capabilities and ideas than others (Bernardo \& Welch, 2001; Simon, Houghton, \& 
Aquino, 2000), outsiders will inevitably discriminate before providing capital to unproven new projects or ventures (Venkataraman, 1997). When the risks and uncertainties become too great, this discrimination may result in market failure, preventing promising but risky ideas from attracting the capital they need to survive.

This fundamental access-to-capital problem is what makes the success of crowdfunding, as evidenced by the example described above, empirically fascinating and theoretically interesting. Even if Pebble is a highly unusual case, it is nonetheless astonishing that any single, two-person startup with few resources could raise over USD \$10 million in four weeks with little more than a web page and a prototype (see Appendix 8.1 for an image of the Kickstarter campaign page for this project). ${ }^{1}$ If this is an illustration of crowdfunding's promise, then the implications for the financing of innovation and early-stage ventures are potentially profound. Many would-be inventors and entrepreneurs who would otherwise be unable to access conventional sources of funding, such as venture capital, may now have a viable alternative that enables them simultaneously to attract funding and build an enthusiastic base of potential (or actual) customers. Empirically there is much that remains unknown and poorly understood about this phenomenon, and this study seeks to deepen our knowledge about how (and why) crowdfunding works, especially regarding the factors that motivate funders to support innovative projects.

\footnotetext{
${ }^{1}$ Eric Migicovsky, the co-founder of Pebble Technology Corp., was a 2009 graduate of the University of Waterloo in Ontario, Canada and just twenty-six years old in 2012, when he first attempted to get funding from venture capital firms; only after he had been uniformly rejected did he attempt to solicit funds from the public through Kickstarter.
} 
Crowdfunding is also theoretically interesting because standard economic theories about the allocation of capital to private enterprise do not fully explain why collectives of private individuals would voluntarily contribute to ventures in the absence of explicit financial rewards. Most venture finance decisions, as described in the literature, emphasize the important role of financial incentives and contractual protections for facilitating the funding of startups (Gompers \& Lerner, 2001; Kaplan \& Stromberg, 2003). However, in the context of most crowdfunding transactions today, neither conventional financial incentives nor contracts are available. In fact, financial returns are explicitly prohibited on the Kickstarter platform; projects may only offer non-monetary rewards or perks (e.g., token gifts) to prospective funders. Moreover, the venture finance literature tends to focus upon investments made by and among only a few classes of institutional investors, such as private venture capital firms or angel investors (Denis, 2004), whereas nearly all crowdfunding is drawn from a less sophisticated public, i.e., the crowd.

Given the dearth of empirical research on the crowdfunding phenomenon and the opportunity to contribute to our understanding of collective decision-making in this context, this paper addresses the following central question: Under what conditions and through what mechanisms do voluntary contributors freely support private enterprise in the absence of financial incentives? Drawing from theories about collective action and the provision of public goods, I first seek to advance a hybrid "private investment-collective action" model for the financing of innovation. Second, I integrate the economic and organizational literature with in-depth fieldwork regarding 
fifteen crowdfunded ventures to develop a more grounded, socially embedded explanation about the private-collective model in the context of crowdfunding. Finally, since qualitative research can sometimes overstate theoretical processes, I complement insights from the field interviews with a quantitative study of 71,304 crowdfunding campaigns. To conclude I supplement the main analysis with a detailed review of 1,316 technology-based crowdfunded projects from within the main dataset; and, in order to establish external validity I conduct a replication of the main analysis with data regarding an additional 22,548 crowdfunding campaigns collected from an alternative crowdfunding platform.

\subsection{Background and context ${ }^{2}$}

Crowdfunding is a method for soliciting financial support from (potentially) large numbers of people through the Internet (Belleflamme, Lambert, \& Schwienbacher, 2010). Using an online portal or third-party platform (e.g., www.kickstarter.com,

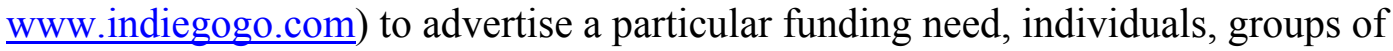
people, or organizations can request money directly or indirectly from other individuals or institutions. Often these solicitations take the form of donations in exchange for rewards or "perks," although many online crowdfunding portals also facilitate funding in the form of uncollateralized debt (e.g., www.prosper.com) or partial equity ownership (e.g., www.symbid.com). Globally there are an estimated 800 crowdfunding platforms (Crowdsourcing, 2013), and the number is expected to continue to grow significantly

\footnotetext{
${ }^{2}$ For a more comprehensive overview of crowdfunding, please refer to Appendix C.
} 
through the decade, particularly following the implementation of the crowdfunding provisions contained in the Jumpstart Our Business Startups (JOBS) Act, signed into law by President Obama on April 5, 2012.

Currently crowdfunding platforms are used to raise money for an exceedingly broad range of purposes, including: making a film, producing music, supporting philanthropic causes, underwriting scientific research, and refinancing personal debt, to name just a few examples. With the high-profile funding success of a number of entrepreneurial projects and the relaxation of regulatory restrictions on equity-based crowdfunding in the United States, the potential for crowdfunding as a method for financing new ventures holds promise. What this means, therefore, is that the financing of innovation may evolve from an essentially private activity to a far more public one.

Historically, venture financing has been the domain of private institutions, such as banks, private equity, venture capital firms, and wealthy private individuals, or angel investors. Broadly speaking, the general public has been excluded from entrepreneurial finance for the following reasons: 1) lack of access to information about attractive investment opportunities; 2) relative lack of sophistication about commercial innovations or the nature of new venture finance; 3 ) low tolerance for risk when faced with complex opportunities that have highly uncertain outcomes; and, 4) regulatory restrictions that impose limits on the number of unaccredited investors who may fund a new venture (Tyebjee \& Bruno, 1984; Wetzel, 1987).

Crowdfunding has the potential to democratize the venture-financing process, offering a wide range of opportunities for anyone to fund an idea or enterprise. While the 
highly public nature of crowdfunding presents a radical change in the process of funding entrepreneurial opportunities, the fundamental information asymmetry between the entrepreneurs and their potential funders remains. In fact, in the context of crowdfunding, we should expect the asymmetry to be amplified since funding campaigns are essentially impersonal solicitations to a broad audience. A pitch for financing may be posted to a crowdfunding site, but this is a far less personal form of engagement than if the entrepreneur or founding team were providing an in-person, face-to-face demonstration of a product or service to a venture capital firm or panel of angel investors. And yet, despite the apparent amplification of the information asymmetry problem, crowdfunded markets do not fail, as theory would predict. In fact, Kickstarter reports that $43.6 \%$ of all projects on its platform have successfully met their funding goals, even though they did not have the various protections and disclosure mechanisms that are available to professional investors.

\subsection{Conceptualizing crowdfunding ${ }^{3}$}

Of course, Kickstarter is not an investment platform, per se, but a reward-based crowdfunding portal. Nonetheless, as the largest and most well-known platform, it offers the best opportunity to explore the dynamics of the crowdfunding phenomenon,

\footnotetext{
${ }^{3}$ By its broadest definition, crowdfunding has a number of variants. For example, it may refer to peer-to-peer (P2P) lending platforms on which large numbers of people offer small loans to applicants in exchange for a financial return on their capital. The term may also include equity-based crowdfunding platforms, where contributors receive an equity share of the project or nascent business. In this paper, I limit the analysis and discussion strictly to the reward-based crowdfunding model, in which contributors receive only tangible perks, gifts or products in exchange for supporting a project.
} 
especially the behaviors and decisions of individuals who choose to support the innovations featured there.

Kickstarter serves as an online pledging system for the financing of creative projects. The platform is open to the public, and every project must be approved by the platform prior to being listed. Funding campaigns are generally time-limited, and they usually last for no longer than a month. Kickstarter imposes an "all-or-nothing" condition on all funding campaigns: projects that fail to reach their funding goal by a predetermined date will not collect any funds from supporters. Also, on Kickstarter all project creators must offer tangible rewards or "perks" to funders in exchange for their monetary contributions; in many cases the reward may be the crowdfunded product itself. Thus, crowdfunding often resembles a pre-sale or pre-commitment for the delivery of a product or service.

These particular features of reward-based crowdfunding are important to understand as we consider the process by which it serves as a financing mechanism for innovation. Conceptually, at least on one level, reward-based crowdfunding is philanthropy. Even though all projects on Kickstarter are required to offer a tangible reward, many of these rewards are simply tokens intended to acknowledge individual contributions (e.g., thank-you notes, key chains, posters, and the like). This is very similar to the way in which people donate to other causes or institutions, often in exchange for small gifts or "premiums" that correspond to different donation amounts.

On another level, reward-based crowdfunding serves as a pre-sales or preordering system; we have observed that many backers on Kickstarter are funding projects 
precisely at or above the particular reward level at which they may expect to receive the "advertised" product. The Pebble watch, discussed earlier in this paper, is likely an example of this type of exchange.

On yet a third level, crowdfunding is financing. Even though Kickstarter does not allow backers to receive equity or to be promised any financial return for their contributions, many project owners (or "creators," as they are called on Kickstarter) are using crowdfunding explicitly to finance their innovations and nascent entrepreneurial ventures; hence backers may be motivated to support a project because they want to be involved and engaged in the start-up of an activity, even though they do not expect to receive financial compensation. So, while backers of projects on a reward-based crowdfunding platform may not be construed as "investors" in the technical sense, they still serve as an important source of financial capital. ${ }^{4}$

Therefore, we may stipulate that crowdfunding backers are a mix of philanthropists, prospective customers, and financers. And, regardless of any particular contributor's orientation, all project backers face the same fundamental challenge: How do they evaluate and select which projects to support when the quality of any given project (and its creators) is highly uncertain? Whether they are philanthropically

\footnotetext{
${ }^{4}$ The literature in venture finance has established that prospective investors will seek to mitigate the risks that arise from the information asymmetry through contractual mechanisms (Gompers \& Lerner, 2001; Kaplan \& Stromberg, 2003) or through socially embedded relationships (Shane et al., 2002; Uzzi, 1999; Venkataraman, 1997) that transfer salient information about the new venture. The issue of risk is an essential point, since financial contributions for crowdfunding campaigns are nearly riskless, but only in the sense that contributions are voluntary. Contributors, however, do face the risk that the project creator will fail to deliver a promised reward or product.
} 
motivated, product-seeking, or investment-minded, the need for information to evaluate product and creator quality is high.

\subsection{Motivation}

With the foregoing in mind, we return to the question that motivates this dissertation: Under what conditions and through what mechanisms do voluntary contributors freely underwrite private innovation in the absence of financial incentives? On the one hand, reward-based crowdfunding platforms do appear to operate as pre-ordering systems for a broad range of innovative products and creative output. From this perspective, we should expect that "backers" (as project funders are called on Kickstarter) would be highly responsive to the tangible incentives offered by each campaign. This suggests a fairly straightforward economic explanation of funder behavior; after accounting for individual preferences, we should expect that funding outcomes will be dependent on these selective incentives. Therefore, the first part of the analysis in this dissertation will test this assumption.

On the other hand, organizational theorists have observed that social factors, such as network ties, reputation, and other forms of social capital, influence the process of innovation and entrepreneurship, including new venture financing (e.g., Baron, 2002; Shane \& Cable, 2002; Stuart \& Sorenson, 2005). Since crowdfunding is predicated on social media and social networking technologies enabled by the Internet, we should also expect that social factors play a role in funding outcomes. Contributing to a project on a crowdfunding platform means being engaged with a larger collective of individuals; thus, 
the logic of collective action should also have a bearing on the outcome of this process. Therefore, the second part of the analysis in this study will explore the effects of these intangible, social factors on funding outcomes.

To address both of these perspectives - private investment motivated by tangible incentives and collective action motivated by intangible social factors - I begin the next section of this paper with a discussion of the private-collective innovation model, derived from an analysis of the open-source software movement (von Hippel \& von Krogh, 2003). This will serve as the foundation for the hypotheses of this paper, which will be further developed with insights from fifteen qualitative field interviews conducted with crowdfunding project creators, founding team members, and their funders. The main analysis will then test the hypotheses with a quantitative study of 71,304 projects that solicited funding on the Kickstarter crowdfunding platform, followed by additional tests with a subset of technology projects on Kickstarter and 22,548 separate campaigns from indiegogo, another popular reward-based crowdfunding platform.

In sum, this research explores the selective incentives and social factors that motivate support for creative projects in the context of crowdfunding. Using qualitative interviews and a large dataset of successful and unsuccessful crowdfunding campaigns, this paper will seek to explain the specific factors that mitigate the information asymmetry problem and ultimately motivate funders to support a project or new idea. 


\subsection{Potential contributions}

By examining the antecedents to investors' decisions under conditions where conventional financial returns are unavailable, this research contributes to the literature in entrepreneurial finance. Since crowdfunding, at least in its current form, offers a financing context where contracts and covenants are not in use, I will seek to isolate other factors that motivate investors toward certain opportunities, thereby shedding light on what helps mitigate the information asymmetry problem. Secondly, by introducing data from crowdfunding, this paper illuminates fundamental features of a new and previously unexplored setting for the financing of innovation and entrepreneurship. Finally, this research will suggest alternative factors - besides financial rewards - that can help motivate support for innovation, creativity, and other entrepreneurial impulses beyond the domain of crowdfunding.

\subsection{Organization}

The next section of this paper discusses the theoretical background, main constructs, and the hypotheses motivating this study. Section Three provides a brief overview of crowdfunding and its related concepts, followed by a detailed description of the sample, measures, and analytic methods to test the paper's hypotheses. Sections Four and Five presents results and discussion, respectively. 


\section{Private-Collective InNovation Model: ReVisited}

This paper seeks to advance a "private-collective" model of innovation, which was initially introduced about a decade ago to explain the open-source software (OSS) movement (von Hippel et al., 2003). Open-source software refers to computer code that is made freely available for public use and development, usually through an online platform. Individual computer programmers, often working within communities of other software developers, contribute their time and expertise toward improving the code for their own use or for others without any direct financial compensation. Contributions to the code are made voluntarily, and any resulting "new" code continues to be published freely for public use. Given the lack of direct, financial incentives for participation in open-source development, the rapid emergence and impact of OSS in the late 1990s appeared to defy conventional economic assumptions about the process of innovation (Lerner \& Tirole, 2002).

\subsection{Private-collective innovation model}

Broadly speaking there are two models for encouraging and rewarding innovation: the private investment model and the collective-action model (von Hippel et al., 2003; von Krogh \& von Hippel, 2006). The private-investment model assumes that innovation will be supported by private investments because private returns can later be appropriated by the investors (Demsetz, 1967). Society deliberately grants innovators and investors in innovation certain protections, such as patents and other contractual rights, so that they may reap profits from their contributions. Given these protections, they also 
have incentives to make further investments toward the development of their ideas in the future. Investors who bear the risk of financing an innovation or new venture likewise have opportunities to structure their commitments in ways that allow them to secure a financial return if the innovation or venture is commercially successful.

The second general approach to innovation is the public or collective-action model (Samuelson, 1954). Under the collective-action model, individuals collectively address social needs and then make their contributions freely available via a "common pool” for the public good (Olson, 1965). By the standard economic definition, public goods are goods that are both non-rivalrous and non-excludable. They are non-rivalrous in the sense that any person's consumption of the good will not diminish any other person's enjoyment of it (Samuelson, 1954); they are non-excludable because it would be impossible to prevent any one person from having access to the good. A classic example of a public good is a lighthouse; the availability and consumption of the lighthouse's benefits (i.e., visibility, safety, and navigation) are essentially unlimited. A loaf of bread, on the other hand, is a purely private good; once it's been consumed by one person, by definition it is thereafter unavailable for consumption by anyone else. Other examples of public goods include over-the-air radio and television broadcasts, fireworks displays, state-sponsored military protection, and, as addressed by von Hippel and Von Krogh, free and open software.

Both models of innovation - private investment and collective action - present problems. In the case of private investment, if the expected rewards are considered insufficient relative to the risks borne by the investor, then the funding of the innovation 
may not occur. In the case of collective action, if all members of a group can enjoy the benefits from the public good, then no individual group member will have an incentive to contribute toward its creation. Motivations of self-interest lead people to wait for others to do their part, essentially enabling them to "free ride" on the efforts of the group. As a result, the public good may not be created as people essentially opt out of the process. In fact, many public goods are not created by the private market, but are instead supported and often created through public expenditure (i.e., by the government through taxation). The funding of basic science and research by the government and its agencies (e.g., National Science Foundation, National Institutes of Health) is an example of a response to the failure of the collective-action model to support innovation.

In von Hippel and von Krogh's (2003) formulation of a "private-collective" model of innovation, they specified that open-source software (i.e., software whose source code is made freely available to anyone via the Internet) is itself the public good. Once created, it is both non-rivalrous and non-excludable. Anyone can download opensource code for free without limiting the amount that is available for anyone else; also, open-source code is infinitely replicable, so no one can be feasibly excluded from having access to it. And yet, despite these characteristics, many thousands of the world's best programmers contribute time and effort toward enhancing a variety of open-source projects without direct financial compensation (Lerner et al., 2002). In the years since the open-source movement first emerged, many other open-source-type projects have 
become common; the regular updating, reviewing, and editing of Wikipedia, the free, Internet-based encyclopedia, is perhaps the best-known example of this. ${ }^{5}$

Since the development of open-source projects entails both private investment (i.e., the private investment of time and expertise by individual programmers and other contributors) and collective action (i.e., communities working toward common goals) von Hippel and von Krogh (2003) suggested that the open-source phenomenon presents a middle ground where incentives for private investment and motivations for collective action co-exist. It is in this sense that this hybrid model of private investment and collective action has relevance for the phenomenon of crowdfunding.

\subsection{Crowdfunding as a response to market failure}

There are circumstances when neither the private nor the collective model alone is sufficient to encourage and reward innovation. Some opportunities may be considered too risky by private investors and too inadequate to merit public support (i.e., by the government). In fact, given the small number of new businesses that receive either public support or venture-capital financing in any given year, there is an acute scarcity of capital available for most innovations and new ventures; the market simply fails to provide necessary funding. ${ }^{6}$ As a result, many inventors and entrepreneurs seek conventional

\footnotetext{
${ }^{5}$ Open-source projects, such as Wikipedia, represent the much larger crowdsourcing phenomenon. Projects, innovations, or ideas are distributed to the public (i.e., the crowd) through the Internet in order to solve a variety of technical and creative challenges. In some cases, incentives are offered to reward contributors for their involvement, and in other cases, such as with open-source software projects, individual contributions are made voluntarily.

${ }^{6}$ According to some estimates, less than one percent of new businesses are funded by venture capital firms (Shane, 2008). Those ventures that do receive venture-capital funding tend to come from only a few high-growth sectors, such as information technology, health care, and clean technology (National
} 
bank financing through loans or consumer credit, but most rely on their personal funds and those of their friends and family. Consequently, many promising innovations and prospective new ventures will fail because they are unable to access the capital they need. It is in the context of this market failure for financing innovation where crowdfunding appears to be playing a role and, as with open-source software development, I suggest that its dynamics may be explained by the private-collective innovation model.

Crowdfunding is related to the open-source software movement in the sense that crowdfunded projects are, like open-source projects, advertised to a "crowd" online. Instead of soliciting technical or creative support, project creators (i.e., the innovators or entrepreneurs themselves) are explicitly seeking financial contributions to underwrite their work. Unlike open-source projects where the software is a public good, crowdfunded projects may or may not be public goods; some campaigns explicitly seek funding for projects that do have broad public benefit, whereas others clearly result in the production of purely private goods (e.g., the Pebble watch). In either case, even though contributors from the "crowd" are not actually creating or changing the good or service, as in OSS, they are certainly supporting and facilitating its creation.

Despite these particular distinctions, crowdfunding mirrors open-source software because it is a process whereby private individuals act in concert (through an online portal) to provide resources to other private individuals in order to support their creative

Venture Capital Association, 2011). Moreover, most venture capital firms today eschew seed-stage investments altogether in favor of later-stage investments in more mature businesses. Consequently, many early-stage entrepreneurs remain excluded from venture capital, and they choose either to self-finance their activities (i.e., through personal savings and credit) or to seek contributions from friends, family, and others in their immediate social network (Birley, 1985; Cooper, 2002). 
projects or endeavors. In exchange, per the platform's participation rules, contributors typically receive a token reward, which sometimes takes the form of the creative project being developed. Therefore, like open-source, crowdfunding has features of private investment (i.e., contributions from individual backers) and collective action (i.e., crowdsupported funding), both of which are in the service of innovation.

\subsection{Selective incentives}

This returns us to the central question of this dissertation, namely: Under what conditions and through what mechanisms do voluntary contributors freely support collective-action efforts to facilitate innovation in the absence of direct financial gain? Lerner and Tirole $(2002 ; 2005)$ raised a similar question in their theorizing about the economics of the open-source software movement. "Why should thousands of top-notch programmers contribute freely to the provision of a public good? Any explanation based on altruism only goes so far" (Lerner et al., 2002, p.198). Indeed, a substantial literature in economics has found that there are limits to altruism for collective action, suggesting that non-altruistic motives dominate in the private provision of public goods (e.g., Andreoni, 1988, 1990). Furthermore, foundational theories about collective action contend that large groups will not act in their common interest (i.e., toward the provision of a public good) unless individual members are offered selective incentives that satisfy their personal needs (Oliver, 1980).

Only a separate and "selective" incentive will stimulate a rational individual in a latent group to act in a group-oriented way. In such 
circumstances group action can be obtained only through an incentive that operates, not indiscriminately, like the collective good, upon the group (Olson, 1965, p.51, emphasis in original).

In the context of crowdfunding contributors $d o$ receive a tangible, if not a financial, incentive because they are often effectively pre-purchasing a reward. Take, for example, a crowdfunding campaign for a film. Let's assume Person A chooses to make a monetary contribution to support this film, and in exchange the filmmakers agree to send Person A an advance DVD copy of the film once it has been produced. Let's also assume that Person B likes the idea for the film and wants to see it someday, but chooses instead not to contribute any money at all, effectively free-riding on the prior contribution of Person A. However, Person B will not receive an advance DVD copy of the movie, and will likely need to wait until the film is publicly available through theatrical exhibition or for sale in some other form. In this way, crowdfunding has resolved the free-rider problem common to collective action efforts by offering selective incentives for contributors. In effect, the private reward for cooperation (i.e., contributing to crowdfunded projects) is significantly greater than the reward for defection, or "free riding" on the contributions of others.

We should expect incentives to be central to the private-collective model, motivating actors (i.e., computer programmers, Wikipedia editors, and crowdfunding "backers") to participate in otherwise uncompensated activities. And, in fact, the literature regarding the open-source software movement offers evidence that "top-notch programmers" (and others) do choose to contribute to the creation of public goods in 
response to a variety of nonfinancial incentives. These incentives include the acquisition of learning and knowledge (Lerner et al., 2005); status and peer recognition (Roberts, Hann, \& Slaughter, 2006); professional acknowledgment (Jeppesen \& Frederiksen, 2006); and career advancement (Lerner et al., 2002).

All reward-based crowdfunding platforms encourage or require campaigns to offer one or more nonfinancial incentives in order to motivate prospective backers. These incentives typically correspond with a range of funding levels. For example, the Kickstarter campaign for the Pebble watch had eleven different reward levels. The smallest level was $\$ 1$; in exchange a backer would receive "exclusive updates" about the campaign. The $\$ 1$ reward level attracted 2,615 backers. The highest reward level for the Pebble campaign was $\$ 10,000$, which offered backers a "mega distributor pack" of 100 watches in any color; this reward level attracted 31 backers. The most popular (i.e., modal) reward level for the Pebble campaign was $\$ 115$, which promised delivery of a single black Pebble watch; this reward level attracted 40,799 backers.

As this example illustrates, the number of reward levels can have a material impact on funding outcomes. Each reward level may address the particular preferences of different segments within the crowdfunding "market," i.e., the subsets of prospective backers who may be interested in supporting a given project. Therefore, this suggests the following hypothesis for the main effect of reward levels:

H1: Selective incentives in the form of reward levels will be positively associated with successful crowdfunding outcomes. 


\section{$2.4 \quad$ Social engagement}

Selective incentives, however, may not be sufficient to explain all of the variability in funding outcomes. First, not all contributors may choose to fund projects at the level at which they are guaranteed to receive a reward. Also, since crowdfunding platforms are not, technically speaking, retail channels, we know that even many successfully funded projects do not deliver their promised rewards or that rewards may be indeterminately delayed (Mollick, 2012). This may indicate that selective incentives may not be the sole or sufficient incentive to freely fund projects through collective action efforts. Therefore, in this section I develop alternative hypotheses to explain the likelihood of successful outcomes in the context of crowdfunding.

Given limited theory about the financing of innovation in the absence of financial gain and given the newness of the crowdfunding phenomenon, I undertake a modified inductive theory-building approach with embedded multiple cases to develop the hypotheses here (Eisenhardt, 1989). "[T]heory-building research using cases typically answers research questions that address 'how' and 'why' in unexplored research areas particularly well" (Edmondson \& McManus, 2007; Eisenhardt, 1989), which suggests the appropriateness of this approach here. The following embedded design has several levels of analysis (i.e., venture, entrepreneur, investor), which should contribute to the development of rich and accurate theory (Yin, 2003).

In order to enrich our understanding of the crowdfunding process and the motivations of contributors, I conducted field interviews with individuals associated with fifteen innovation projects or new ventures that had actively solicited funding through the 
Netherlands-based crowdfunding platform, Symbid (refer to 8.2 in Appendix B for an example of a Symbid project page). The sample included nine projects that had successfully achieved their funding goals and six that had not, as of December 31, 2012. Gaining access to crowdfunding contributors and project owners in a systematic way can often be extremely challenging, but the principals of Symbid provided direct contact with all of the company founders, founding team members, and funders who had been active on the Symbid crowdfunding platform. Each interview was conducted in English via Skype; audio recordings of the interviews were made, and transcriptions of the conversations with informants provided the basis for analysis and hypothesis development.

Entrepreneurs, like all economic actors, are embedded in networks of personal and professional relationships (Aldrich \& Zimmer, 1986; Granovetter, 1985; Johannison, 2000; Larson \& Starr, 1993). These social networks have the potential to influence every stage of the entrepreneurial process, including the discovery of an opportunity (Venkataraman, 1997), team formation (Aldrich \& Kim, 2007), acquisition and assembly of resources (Starr \& MacMillan, 1990), and the growth and performance of the new venture (Cooper, 2002; Stuart et al., 2005). Especially during the early stage of a venture, the founder or founding team's social networks can play a vital role in the mobilization of resources; prior research has demonstrated how entrepreneurs use their networks to acquire resources such as information, advice, technology, human talent, and financial capital (Shane et al., 2002; Stuart \& Sorenson, 2007; Uzzi, 1997). 
Social network-based research in the context of entrepreneurship has flourished in recent years, and much of it has examined the influence of founders' and firms' networks on the development and performance of new ventures (for reviews, see Hoang \& Antoncic, 2003; Slotte-Kock \& Coviello, 2010; Stuart et al., 2005, 2007). A number of organizational scholars have also documented how venture capitalists use their social ties and network relationships to gain relevant information about founders and in order to reduce uncertainty and even prevent bad behavior through norms of social obligation (Shane et al., 2002; Uzzi, 1999).

Since crowdfunding is predicated on the model of social media platforms (e.g., Facebook, LinkedIn), it has been designed to be inherently "social" in the sense that funders and fundraisers are encouraged to connect and share information with one another - before, during, and after any economic exchange. So, even though the ties between and among actors in this setting may be weak, it is nonetheless the presumption that they will be actively engaged with one another. Drawing from the work of researchers who have established the importance of non-economic factors in economic transactions (Granovetter, 1985), I suggest that project creators who leverage their nonfinancial resources in order to establish their legitimacy and directly engage with their backers and prospective backers will be more effective at reaching their goals.

The field interviews provided some evidence that these nonfinancial factors, in the form of direct and indirect engagement with prospective and committed contributors, were important in the funding process. The creator of one of the most successful and 
quickly funded projects on Symbid talked about how being open and communicative with his contributors through the crowdfunding platform was an essential part of his approach:

My strategy was simple: Be honest, answer all the questions within a day, get a good plan, make nice films [i.e, videos for the crowdfunding page]. So, the plan and the information on the site had to be good. The questions, very fast answered, and people who wanted information, if they wanted information, they could get it immediately.

Since these written communications are occurring openly and publicly on the platform, transparency also was a critical feature of this effort. One entrepreneur described how he first tried to raise funds privately but then the use of a crowdfunding platform transformed the process by making it public:

I am so glad I did this publicly because before I did it privately and nothing happened really, and I was very, very slow and total... it was just leading to failure. The moment I went public with this and people started giving input and all these interactions about going in, it's like I said it's like it exploded. And it was really I'm so happy I posted on Symbid. Otherwise, look at now, 100,000 Euros we raised from nothing in January.

Similarly, another entrepreneur described the public discourse and the transparency of the conversations about the projects online as a factor in his success:

There is the information I provided, and there is the information, the questions from the investors. And these questions are -- most everybody can see the questions, and if they are answered right, everybody can see 
that. So the investors do have influence when they question some things. I got very serious questions about the plan and finance part of the plan from people who knew -- were very, very, I call that -- from the administrators asked questions, accountants.

Finally, the interviews also provided insights about the motivations of funders, suggesting factors other than tangible incentives. One consistent theme was the idea that contributors valued their involvement in the campaign, even if this was only virtual. "The strangers [as opposed to friends and family members] on the other hand they are quite interested," said one entrepreneur. "They read the updates. They keep track of what's going on. They like to be involved.” Another emphasized the importance of personal contact:

Personal contact is very important, more insights and where the business is going. But yes, usually the contact.... If something really inspires them, they want to be more involved. Because they are more in it with, they believe in the start of energy, they believe in supporting an entrepreneur in that way. But they are not only in it for the money, then. It's a lot of sort of soft feelings for them as well, funnily enough.

Beyond the contact, entrepreneurs talked explicitly about how contributors literally wanting to be "part of the story":

Yes, we had a lot of questions from investors asking us, hey, we want to know more about how you do this and how you make this happen. They want to be part of the adventure and part of the story. Yes, that's what we heard from our investors actually. 
This same entrepreneur even cited the example of the Pebble watch to reinforce this point:

When you see five nerds creating a watch which is really cool, a really cool gimmick, for like a hundred dollars, why not fund it for ten million?

That's about making it happen and being part of something. When someone wears their watch, people say, "Hey, we raised together with 17,000 [sic] thousand people, we raised ten million dollars for this project, and it's awesome and cool."

Thus, theoretical arguments from the organizational literature regarding nonfinancial, social factors that motivate participation, combined with the insights provided by the field research about the importance of direct engagement with contributors, suggest the following hypothesis:

H2a: Social engagement in the form of direct project updates will be positively associated with successful crowdfunding outcomes.

Related to engagement is the degree to which the number of people in a project owner's online circle may also be important. In the emerging stream of research about crowdfunding, online friendships have been found to be important resources, even signals of credit quality (Lin, Prabhala, \& Viswanathan, 2011). Specifically, friendships increase the probability of successful lending, lower interest rates on funded loans, and appear to have (ex-post) lower default rates. Similarly, it has been shown that crowdfunded loans (i.e., on P2P lending platforms) that have endorsements or bids from friends also have fewer missed payments and better rates of return (Freedman \& Jin, 2008). Finally, 
Mollick (2012) showed that if the sponsor of a film project on Kickstarter had only ten "friends" on their Facebook account, then their probability of getting their project fully funded on Kickstarter was about 9 percent. If the project sponsor had 100 Facebook friends, then their funding probability rose to 20 percent; finally, if the sponsor had 1,000 Facebook friends, then their likelihood of getting fully funded was 40 percent.

Field interviews with entrepreneurs who used crowdfunding platforms to attract financing for their projects or businesses, supports the thesis that personal networks and network ties are important. The interviews highlighted two aspects of social networks: first, the availability of a strong and extensive pre-existing network as a resource; and, second, the willingness of the entrepreneur and her team to utilize that resource. One entrepreneur whose campaign was successful described the process in significant detail:

And so before I went live [with the campaign] I had actually created a database of everyone that I'd ever come across in my life for whom I had the email address.... So that mostly meant my Linked In contacts, my personal email contacts, my business email contacts, and I combined all of my mail addresses, contact folders and Linked In with Facebook or Twitter or whatever. I combined it into one set of people in it. I came to 1,100 people.... So 1,100 people and I thought I'm just going to write to every single person on that list personally, that's what I'm going to do. And so somewhere in January I agreed with my wife that she was going to take care of the kids for a weekend and I was going to you know work. I chose the espresso factory here in the neighborhood. And I sat down and I just started to write people emails about how I would love for them to join you know this pitch. And I started, I must say, I started with the family first, okay, because later that proved to be right. They invested without 
looking at anything....They invested just because it was me, okay. They didn't invest large sums, but they went... it got me over that first hurdle of having nothing. And I think maybe the first thousand or the first two thousand was really family and close friends you know. So that worked. And by the way, I never got over the first 200 people in that list. The other 900 I've never written even today. I haven't written them yet.

The significance of concentric circles of contacts with whom to engage was also a consistent theme across the interviews. One entrepreneur talked about how she worked with her founding team to leverage a broad network in a personal way:

It was successful but what we also did is really connect to the first inner circle, the friends, family. Why it was successful was because we really made it very personal. Every one of us, we had a team of about 18, 19 employees in [our company] really reaching out to the direct network. So it was the community but it was also reaching out to the network. And if someone, if you were part of the community and then somebody asked you personally, then it is successful. But it could also be my father invested as well because of the idea and because I made a pitch for it.

For many this personal engagement was most successful when it extended beyond an "inner circle" of direct personal ties, and led to the activation of indirect ties:

We are not famous here or something, but we have a great network. And if you first show it to your network, that's the most important thing of crowdfunding. You have to first let your friends in your own network invest in it. They will invest in it. You only have to ask them to share it. If you share it, then that's what we made happen. If you do that, you know, 
my mother, my father, my sister, my friends just invested because they liked the idea and they like to support me. You know. And if they started talking about it then -- even my stepmother started talking about it, like, to her network. And that's -- yes, it's all about the people and the idea.

Therefore, the theoretical arguments about the importance of social ties in financing decision and the observation from the field interviews suggest the following corollary to the previous hypothesis:

H2b: Social engagement in the form of direct network ties will be positively associated with successful crowdfunding outcomes. 


\section{RESEARCH DESIGN}

I propose testing the hypotheses developed in the foregoing section using a sample of successfully and unsuccessfully funded project campaigns from Kickstarter, one of the largest and most well-known crowdfunding platforms.

\subsection{Sample}

The sample of crowdfunding campaigns for this study has been selected from Kickstarter, which was first launched in April 2009. The sample consists of publicly available data regarding 71,304 individual project campaigns that occurred between April 2009 and January 2013; 34,262 of these campaigns successfully reached their funding goals and 37,042 did not. ${ }^{7}$ All campaigns that had ended by December 31, 2012 were included in the sample; 1,544 campaigns that were still pending at that time were excluded, as well as six campaigns that were halted due to undisclosed disputes regarding intellectual property issues.

The average goal size for all campaigns was $\$ 13,930$; the average total amount actually funded was $\$ 6,012$ across an average 81 funders. The Kickstarter platform places all projects in one of the following thirteen categories: Art, Comics, Dance, Design, Fashion, Film, Food, Games, Music, Photography, Publishing, Technology, and Theater. Projects in the "Film \& Video" (27\%) and "Music" (25\%) categories dominate in terms

\footnotetext{
${ }^{7}$ Kickstarter does not provide data directly to researchers; information about prior funding campaigns on the platform was retrieved from the Internet using a web data extraction service. This was necessary because Kickstarter indexes any failed campaigns so that they are no longer visible on the Kickstarter website. The aggregate number of failed and successful campaigns was consistent with aggregate figures reported by Kickstarter on its website.
} 
of the overall number of funding campaigns. Projects in the "Design," "Games," and "Technology" categories attracted the highest funding amounts, on average (approximately $\$ 25,000$ each); these three categories also attracted the largest number of funders, on average (287 for Design, 382 for Games, and 234 for Technology). A complete summary of means for characteristics of all campaigns appears in Table 7.1 in the appendix, which illustrates the variability in the sample along several dimensions and across all thirteen project categories.

As indicated on the platform's website, every project must have a clear goal, and it is expected that an artifact or clear deliverable will be produced as a result of a successful funding campaign (e.g., a book, a work of art, a performance, a software application, an event). The Kickstarter platform is "curated" in the sense that project creators must apply and be accepted by the Kickstarter team before their project will be featured on the site. However, projects are only screened to determine if they meet the site's project guidelines; they are not evaluated on the basis of their quality or the qualifications of the project team.

Kickstarter has a "fixed/all-or-nothing" funding model. Campaigns run for a limited or fixed period of time (usually about thirty days); if the project's funding goal is not reached by the end of that period, then no pledges are collected from any funders. For projects that successfully reach their funding goals, Kickstarter charges a $5 \%$ fee on the total amount funded; in addition, there is a 3\% to 5\% fee charged by Amazon for the processing of payments. The remainder goes directly to the project creator. Projects that 
fail to meet their funding goals during the duration of the campaign, which typically lasts three or four weeks, are charged nothing.

Project creators are required to offer specific rewards to supporters across a range of funding levels, as is commonly done during fundraising campaigns in the arts or for public radio. Specific rewards are determined by the project creators themselves, and they may include personal acknowledgments (e.g., having a backer's name appear in the credits of a movie), t-shirts, bumper stickers, or other trinkets related to the project, or they may include a delivery of the product or itself (e.g., future delivery of a DVD copy of the movie being produced). If the project reaches its funding goal, Kickstarter stipulates that project owners are "legally required" to deliver all promised rewards. However, the mechanism for enforcing delivery is vague. ${ }^{8}$

\subsection{Dependent variable: Funding outcome}

The dependent variable, funding outcome, was a binary variable of one if the project reached its funding goal and a zero if it did not. For a subsequent analysis I operationalized the dependent variable as the percentage of the funds pledged relative to the campaign's funding goal (percentage of goal). Since each campaign was seeking different amounts of funding and since the reward levels for each campaign varied widely, the relative amount of funding would be a better measure of success when comparing projects of different sizes. Also, as mentioned earlier, Kickstarter is an all-ornothing system: any project that does not reach its goal will not collect any funds,

\footnotetext{
${ }^{8}$ Kickstarter's website further explains: "Backing a project is more than just giving someone money, it's supporting their dream to create something that they want to see exist in the world." http://www.kickstarter.com/help/faq/kickstarter\%20basics?ref=nav, Accessed 11 March 2013.
} 
regardless of the number and amount of pledges it has attracted. The funding goal and the total amount pledged are reported directly on each campaign page.

\subsection{Independent variable: Selective incentives}

Project creators are required by Kickstarter to offer tangible rewards as incentives to prospective funders; however, they have discretion regarding how many levels of rewards to offer. Each campaign page on Kickstarter typically reports a range of reward levels; I have operationalized selective incentives for each campaign as the number of reward levels available to funders. The following table reports descriptive statistics for reward levels on Kickstarter.

Table 3-1 Descriptive statistics for reward levels

\begin{tabular}{|l|l|}
\hline Number of Reward Levels $(\mathbf{N}=\mathbf{7 1 , 3 0 4})$ \\
\hline Mean & 8.24 \\
\hline Median & 8.00 \\
\hline Mode & 7.00 \\
\hline Standard deviation & 4.71 \\
\hline Minimum & 9 \\
\hline Maximum & 0 \\
\hline
\end{tabular}

\subsection{Independent variable: Social engagement}

Each project page on Kickstarter contains both direct and indirect measures of social engagement. The most direct measure of the degree of engagement provided by the project owner was captured in the number of updates that the project owner provided during the course of the campaign. Kickstarter encourages all project owners to post

\footnotetext{
${ }^{9}$ Only two projects in the sample offered no rewards, but the data has been included here for completeness; neither campaign reached its funding goal.
} 
information to their project page in order to keep current or prospective backers engaged in the campaign and the project itself. Not only are these updates presented on a special section of each page in reverse chronological order, but the number of updates is reported directly at the top of each project page.

Table 3-2 Descriptive statistics for project updates

\begin{tabular}{|l|l|}
\hline \multicolumn{2}{|l|}{ Number of Updates (N $\mathbf{~ 7 1 , 3 0 4 )}$} \\
\hline Mean & 4.41 \\
\hline Median & 2.00 \\
\hline Mode & 0.00 \\
\hline Standard deviation & 7.12 \\
\hline Minimum & 0 \\
\hline Maximum & 284 \\
\hline
\end{tabular}

The other measure of a project owner's degree of engagement with her (prospective or actual) community of supporters was somewhat more indirect: the extent to which she used her network of social media contacts to engage with her Kickstarter campaign. All project owners have the opportunity to link their Facebook account, if they have one, with their Kickstarter project page. ${ }^{10}$ For those owners who do establish this link, their Kickstarter page indicates this connection and reports the project owner's number of "friends" on Facebook. The reason this is an indirect measure of engagement is that we do not know the extent to which project owners actually leveraged this particular social-media network to generate support for their campaigns. However, the very existence and relative strength of a social media network (i.e., number of Facebook "friends") can serve as a proxy for the ability of a project owner to use these tools to

${ }^{10}$ Some Kickstarter campaigns provide a link to a personal Facebook account page for the project creator, whereas others link to a dedicated project or company page on Facebook; these distinctions were not coded for this analysis. 
establish direct connections with her prospective funders. If an owner connected her Facebook account to her Kickstarter page, then her total number of "friends" is reported next to her name and profile on her project page. Table 3-3 provides descriptive statistics for the subset of Kickstarter campaigns that included a link to a Facebook account $(N=$ 26,434).

Table 3-3 Descriptive statistics for Facebook friends

\begin{tabular}{|l|l|}
\hline Number of Facebook friends $(\mathbf{N}=\mathbf{2 6 , 4 3 4})$ \\
\hline Mean & 435.39 \\
\hline Median & 404.00 \\
\hline Mode & 120 \\
\hline Standard deviation & 261.17 \\
\hline Minimum & 1 \\
\hline Maximum & 999 \\
\hline
\end{tabular}

\subsection{Control variables}

To provide more accurate estimates for the hypothesized variables I have controlled for other factors that affect the likelihood of a successful funding campaign. First, it is likely that the intended size of a funding goal will have a bearing on the funding outcome; campaigns with very modest funding goals (e.g., \$100) are more likely to be successful than those that have more ambitious targets (e.g., $\$ 100,000)$. Therefore, I have controlled for the log of the funding goal (Tyebjee et al., 1984; Wetzel, 1987).

Similarly, I controlled for the duration and funding goal for each campaign. The Kickstarter platform permits campaigns to run from one to 60 days, although the 
platform's guidelines encourage projects to target 30-day limits. ${ }^{11}$ Since the length of a campaign in days will affect the chances of successful funding (i.e., very short campaigns of only a few days will have less opportunity to generate interest and attention than those lasting several weeks), I used the log of each campaign duration to control for this potential variability. Also, since each project was generally seeking different amounts on financial support over different periods of time, following Mollick (2012) I controlled for the log of the size of the funding goal.

I also controlled for other dimensions of project quality that previous research has found to be important for explaining venture finance decisions. For example, Delmar and Shane (2003) found that certain activities undertaken by entrepreneurs, such as business planning, may yield greater legitimacy and thus may have a positive impact on early venture survival. Other legitimacy-enhancing practices, such as adopting or mimicking organizational structures or ceremonial activities common within a certain industry or environment can contribute to firm survival and growth (Khaire, 2012). An example of this form of preparedness and legitimation is the presence or absence of a website for each project. Approximately $61 \%$ of all projects in the sample provided a link to a website external to the Kickstarter page for the campaign; many of these websites offered additional information about the projects and their creators. I used a dummy variable to indicate whether the project provided a link to an external website or not.

\footnotetext{
${ }^{11}$ Kickstarter's guidelines suggest the following: "Funding can last anywhere from one to 60 days, however a longer duration is not necessarily better. Statistically, projects lasting 30 days or less have our highest success rates. A Kickstarter project takes a lot of work to run, and shorter projects set a tone of confidence and help motivate your backers to join the party. Longer durations incite less urgency, encourage procrastination, and tend to fizzle out." Source: kickstarter.com/help/school\#setting_your_goal Accessed: 20 April 2013.
} 
Prior research in venture capital has found that investors tend to favor certain industries over others (Haar, Starr, \& MacMillan, 1988). Also, given the breadth of project categories on Kickstarter, we should expect variability in funding patterns across them. Therefore, I controlled for this potential variability by dummy coding each of thirteen project categories in the sample. 


\section{Results}

This first part of this section describes from the results from the main analysis of funding outcomes for the 71,304 observations in the sample. This discussion is followed by a series of robustness checks, including internal validation using a subset of technology projects and an external validation using a comparable set of 22,548 projects from a secondary data source.

\subsection{Main analysis}

Table 7.2 in the appendix shows the descriptive statistics and Pearson correlation matrix for the control and predictor variables of the complete set of Kickstarter projects $(N=71,304)$. Nearly half of all projects in the sample achieved or surpassed their funding goal, indicating that the sample is evenly weighted. None of the variables are highly correlated with one another, suggesting variable independence within the sample.

Table 7.3 presents the results of the logistic regression predicting the likelihood of funding success as a function of selective incentives and social engagement factors, controlling for other factors. Model 1 is the base model, which includes the control variables for the $\log$ of the overall size of the funding goal and the duration of the campaign; an indicator for project quality and the preparedness of the project creator (dummy variable for the presence of a project website); and, finally, dummy variables to control for each of the thirteen project categories (Art, Comic, Dance, Fashion, Film \& Video, Food, Games, Music, Photography, Publishing, Technology, and Theater). The results in Model 1 indicate that, as expected, among the control variables, the size of the 
funding goal $(\operatorname{Exp}(B)=-0.93, \mathrm{p}<0.001)$ predicted a lower likelihood that a project would be fully funded; the same was true for the duration of the campaign $(\operatorname{Exp}(B)=-$ $0.36, \mathrm{p}<0.001)$, although this effect was only slight. The results do show, however, that the presence of a project website $(\operatorname{Exp}(B)=0.55, \mathrm{p}<0.001)$ was positively associated with funding success. Overall the model accounts for a little more than 15 percent of the variance in he expected outcome (pseudo $\mathrm{R}$ square $=0.156$ ).

Models 2 and 3 each show the individual effects of incentives (reward levels) and social engagement (project updates and Facebook friends) on the funding outcome. Each of these variables has significant effects on whether a project achieves or exceeds its funding goal. As predicted, Model 2 shows that the number of project reward levels is strongly and positively related to the likelihood of project funding $(\operatorname{Exp}(B)=1.15, \mathrm{p}<$ 0.001 ), suggesting that incentives are a significant factor in the funding process. The addition of this measure also improves the model's fit to the data relative to the base model (pseudo R square $=0.226$ ), explaining about 22 percent of the variability in the outcome. Model 3 shows that social engagement is also, as predicted, strongly and positively related to the likelihood of full funding, although the number of project updates accounts for most of this effect $(\operatorname{Exp}(B)=1.45, \mathrm{p}<0.001)$; the number of Facebook friends is non-significant. The fit of this model is excellent, explaining over 57 percent of the variability in the relationship.

Model 4 examines both constructs, selective incentives and social engagement, together. The model shows that the effects of selective incentives $(\operatorname{Exp}(B)=1.04, \mathrm{p}<$ 0.001) are mitigated when social engagement variables are also considered. The 
influence of the project creator's Facebook friends is statistically significant, but negligible $(\operatorname{Exp}(B)=0.00, \mathrm{p}<0.001)$, and the effect of project updates remains strong $(\operatorname{Exp}(B)=1.44, \mathrm{p}<0.001)$. Model 4 has approximately the same explanatory power as Model 3 (pseudo R square $=0.574$ ).

It is also possible that selective incentives (i.e., rewards) and social engagement factors (i.e., updates and Facebook friends) have multiplicative effects on the probability of funding success rather than additive effects. I explored whether interactions between rewards and updates, between rewards and Facebook friends, and between updates and Facebook friends had any significant effect on the likelihood of project funding. I found no significant effects for any of the interactions, reinforcing the finding that updates alone have the main influence on outcomes.

\section{Replication with linear regression}

In the main analysis we examined only the binary outcome of whether a project achieved its funding goal or not. Since the dataset for our sample also includes information about relative and not merely absolute funding, we can use linear regression estimation to further test the strength of our hypotheses.

Kickstarter maintains an "all-or-nothing" requirement for all campaigns, such that projects unable to meet their funding goal within a specified funding period will not be permitted to collect any funds from their backers. Nonetheless, since we know the aggregate amount of money that was pledged for every campaign, we can estimate the effects of our hypothesized variables on the relative funding achieved by each campaign 
(i.e., amount pledged as a percentage of the funding goal). Since this is a continuous outcome variable, an ordinary least squares (OLS) linear regression is appropriate.

Results from the linear regression replicating the analysis in the previous section appear in Table 7.4 in the appendix. Consistent with the approach using logistic regression the models here show the influence of selective incentives and social engagement factors on the funding outcome, both individually and in combination. Model 2, which includes the measurement of reward levels, is statistically significant (Fstat $=864.7, p<0.001)$ and explains about 17 percent of the variation in the amount of funding (Adj. R-square $=0.171)$. However, as we also saw in the logistic regression analysis, the models that include social engagement factors (Models 3 and 4) have substantially more explanatory power than the others (Model 3 Adj. R-square $=0.355$; Model 4 Adj. R-square $=0.335$ ). Therefore, the effects of rewards, updates and Facebook friends on the relative funding amount is consistent with the effect we found for the likelihood of a project being successfully funded in the earlier analysis. The influence of updates dominates.

\subsection{Robustness tests}

\section{Internal validation}

The breadth of projects included in the Kickstarter dataset is robust, which should improve our confidence in the strength of the findings. However, it is also possible that the results are spurious, an inadvertent function of the wide variability among projects. 
Therefore, in order to control for that variability and to test for the internal validity of my findings, I have also tested my hypotheses within a single project category: Technology. Technology represents a special project category on Kickstarter since the platform imposes specific requirements for these projects. In order to solicit funding for a project in the Technology category, project owners must: 1) demonstrate a functional prototype on their Kickstarter page (e.g., using video or photographs); 2) provide detailed information about the project creators' experience; 3 ) describe the manufacturing plan to ensure that funders will receive their rewards (when relevant). ${ }^{12}$ These requirements suggest that Technology projects are generally developing tangible products, whereas many other projects in Arts, Dance, and Music, for example, are not creating clear deliverables. Also, Technology projects are often seeking funding to create products (e.g., hardware, software) that are replicable, scalable, and commercializable. So, even though Kickstarter stipulates that the purpose of "starting a business" is not appropriate for Kickstarter, many of the technology and design projects on Kickstarter clearly have the potential to be the basis for a commercial enterprise, more so than projects in other categories. $^{13}$

The Kickstarter dataset includes 1,316 projects in the Technology category. Technology represents only two percent of all projects seeking funding on Kickstarter (see Table 7.1 in the appendix). However, relative to all other funding categories on the

\footnotetext{
${ }^{12}$ Kickstarter has similar requirements for projects in the Product Design category.

${ }^{13}$ Kickstarter's website stipulates: "Backing a project is more than just giving someone money, it's supporting their dream to create something that they want to see exist in the world." http://www.kickstarter.com/help/faq/kickstarter\%20basics?ref=nav, Accessed 11 March 2013.
} 
platform, Technology projects had the second highest average goal size $(\mu=\$ 24,998$, S.D. $=\$ 54,473)$ and the second highest average amount funded $(\mu=\$ 24,845$, S.D. $=$ $\$ 131,021) .{ }^{14}$ Thirty-nine percent of all Technology projects (i.e., 510 campaigns) achieved or exceeded their funding goal. In addition, Technology was among the top three project categories with the highest average number of individual funders $(\mu=234$, S.D. $=820) .{ }^{15}$ Therefore, Technology projects are among the most highly funded and highly supported projects on the Kickstarter platform, yet they do not represent the most extreme cases, and they therefore exclude many outliers (e.g., the Pebble watch is included in the Design category, not Technology).

In order to improve the reliability of our models, additional variables were included as controls in the analysis. As discussed earlier, previous research has found that certain organizing activities can both legitimize a new venture (Delmar et al., 2003; Delmar \& Shane, 2004) and offer identifiable signals of venture quality to prospective funders (Chen, Yao, \& Kotha, 2009). For the crowdfunding campaigns that we had analyzed earlier in this paper, we used the presence or absence of an external website as a proxy signal for project legitimacy and quality; this was included as a control variable in all the models.

\footnotetext{
14 "Games," which account for five percent of all projects listed, had the highest average goal size $(\mu=\$ 27,861, S . D .=\$ 84,817)$; for comparison, the average funding goal for all Kickstarter projects in the sample was $\$ 13,930(S . D .=\$ 195,152)$. "Design," which accounts for three percent of all projects, had the highest average funding amount $(\mu=\$ 25,459, S . D .=\$ 227,713)$; the average total amount raised for all projects was $\$ 6,012(S . D .=\$ 65,413)$.

15 "Games" had the highest average number of funders ( $\mu=382$, S.D. $=2,636)$; "Design" had the second highest average number of funders $(\mu=287$, S.D. $=1,651)$. For comparison, the average number of funders for all Kickstarter projects was $81(S . D .=682)$.
} 
Here, in order to strengthen further the controls for project quality, perceived legitimacy, and overall preparedness among the subset of 1,316 Technology projects, two independent research assistants coded (or extracted) the following additional variables for each Technology project page: 1) the presence or absence of a video explaining the project (dummy coded as a one if a video was present); 2) the number of other projects created by each project creator; 3) the number of projects "backed" or supported by each project creator; and, 4) a dummy variable to indicate whether the reward levels included at least one opportunity for prospective backers to pre-purchase the technology. ${ }^{16}$

The four additional variables (i.e., video, projects created, projects backed, and product delivery available) were specifically included in order to strengthen the controls for quality and legitimacy in the main models. Following recent work that has addressed similar issues in crowdfunding (Kuppuswamy \& Bayus, 2013; Mollick, 2012), the presence of the video is operationalized as a signal for the preparedness and quality of the project. The number of Kickstarter projects created and the number of Kickstarter projects backed are indicators of the experience of the project creator; we should expect that creators who have supported other projects or who have had more experience creating other projects of their own will be better equipped and, hence, more effective at executing a successfully funded campaign. Likewise, the dummy variable for the ability

\footnotetext{
${ }^{16}$ Despite the appeal of Kickstarter as a pre-ordering system for new products and technologies, many campaigns do not offer any pre-purchase options among their rewards. For example, a high-school science club may create a Kickstarter campaign to raise funds for a school project; this project may not result in any particular artifact or technology that a backer could conceivably pre-order. Therefore, the research assistants examined the set of rewards available for each Technology-related project on Kickstarter to determine whether the funded product could actually be delivered; if that were possible, then it was dummy coded as a one. Table 7.5 shows that about $66 \%$ of all Technology projects provide the option to pre-order the funded product or service.
} 
of a backer being able to pre-order the funded product or service provides a further signal of product quality to prospective funders.

Table 7.5 in the appendix presents descriptive statistics and correlations for the sample of 1,316 technology projects. About 40 percent of technology projects were successfully funded, which is somewhat lower than the 48 percent success rate for all Kickstarter projects. The average number of rewards offered $(\mu=8.02)$ was largely consistent with the main sample $(\mu=8.20)$; whereas the number of updates posted $(\mu=$ 6.41) was somewhat higher than for the main sample of all projects $(\mu=4.40)$.

Table 7.6 provides the results of the logistic regression estimations predicting whether a project met its funding goal. Similar to the logistic regression models for the full sample of all projects, the model for the technology sample includes controls for the $\log$ of the size of the goal, duration of the campaign, and whether the project provided a link to an external website; not included, of course, are controls for project category. The additional control variables for this analysis included the presence of a video on the project page, the number of projects created by the project owner, the number of projects backed by the project owner, and a dummy variable to indicate whether the project offered an opportunity to pre-purchase the crowdfunded technology. As before, the predictors were the number of rewards, updates, and Facebook friends.

Model 1 is the base model, which excludes all of the predictor variables. Consistent with the main analysis of all projects, the goal size was statistically significant and negatively related to funding success. The presence of a website $(\operatorname{Exp}(B)=2.30, \mathrm{p}<$ 0.001), a video $(\operatorname{Exp}(B)=2.44, \mathrm{p}<0.001)$, and the number of projects created $(\operatorname{Exp}(B)=$ 
$1.05, \mathrm{p}<0.001)$ were all significant and positively related to project funding success, suggesting that overall preparedness, experience, and other signals of quality and legitimacy have an effect on funding. The control variables alone explain about 19 percent of the variability in the dependent variable (Nagelkerke R-square $=0.186$ ).

Model 2, which adds the predictor variable for the number of rewards, has somewhat more explanatory power than the base model, but not significantly more so $($ Nagelkerke R-square $=0.266$; Chi-square $=287.2)$. Here we find that having more tangible incentives, operationalized as the number of rewards, is significant and tends to increase the likelihood of funding success $(\operatorname{Exp}(B)=1.19, \mathrm{p}<0.001)$.

Model 3, which includes only the social engagement predictors (i.e., number of updates and number of Facebook friends), is dramatically more powerful than Model 2, explaining nearly 70 percent of the funding outcome (Nagelkerke R-square $=0.694)$; likewise the Chi-square indicates that this model has a much better fit to the data (Chisquare $=456.2$ ). As in the logistic regressions for the main sample of all Kickstarter projects, this model suggests that most of the effect results from the number of updates $(\operatorname{Exp}(B)=1.49, \mathrm{p}<0.001)$ and not the number of Facebook contacts $(\operatorname{Exp}(B)=1.00, \mathrm{p}<$ 0.01). Model 4 includes all three predictor variables, although its predictive power is not significantly improved over Model 3 (Nagelkerke R-square = 0.697; Chi-square $=458.3$ )

Finally, for the sake of consistency and completeness, I also conducted a linear regression with the technology project data in order to assess the effect of the predictor variables on the amount of funding relative to the funding goal (see Table 7.7). Again, we find that rewards alone are a statistically significant predictor of funding success, 
although the model itself is not especially strong $(\mathrm{F}$-stat $=12.0 ;$ Adj. $\mathrm{R}$-square $=0.063)$. However, once again, when we consider the effects of social factors in Models 3 and 4, the model's explanatory power is significantly greater (Model 3: Adj. R-square $=0.176$; Model 4: Adj. R-square=0.189).

In sum, the results of the analysis of the subset of technology projects show strong internal validity for the findings from the main analysis of all projects.

\section{External validation}

By most public reports Kickstarter represents the largest and most well-known reward-based crowdfunding platform in the United States. Therefore, the large sample of crowdfunding campaigns selected for this analysis is likely to be sufficiently robust and representative, such that it is capable of revealing fundamental characteristics of the phenomenon. However, it is also possible that the dynamics observed are unique to Kickstarter's environment or to the cohort of project creators and project backers who have selected Kickstarter's platform to participate in reward-based crowdfunding. Therefore, in order to test the external validity for our results, I have collected a largely comparable dataset from another large crowdfunding platform.

Data for an additional 22,548 reward-based crowdfunding campaigns was collected from indiegogo, a crowdfunding platform that shares many of the same features as Kickstarter. Launched in 2008, the indiegogo platform was established to serve independent filmmakers seeking capital to create film and video projects. Since that time indiegogo has broadened its mission, and it now supports funding campaigns across 24 different categories; these projects are further organized into three supra-categories: 
Cause, Creative, and Entrepreneurial. ${ }^{17}$ Unlike Kickstarter, however, indiegogo does not restrict campaigns only to "creative projects," and it will entertain funding campaigns for new businesses, social causes, and even political campaigns (see 8.3 in Appendix B for an example of an indiegogo campaign page). Nonetheless, like Kickstarter, it is still a curated platform in the sense that campaigns must first be approved before they are featured in indiegogo.

One other important distinction between indiegogo and Kickstarter is that indiegogo does not require project creators to adhere to an "all-or-nothing" campaign. Project owners may choose to follow an all-or-nothing approach, which indiegogo calls a "fixed" campaign; if they do, then indiegogo collects only a four percent fee. If project owners choose to run a "flexible" campaign, then they may collect all monies pledged, but indiegogo collects a nine percent fee. In either scenario, a three percent third-party credit card processing fee is also imposed. Finally, like Kickstarter, indiegogo strongly suggests that project creators offer reward to prospective backers, but unlike Kickstarter, indiegogo does not require these rewards.

For the purpose of this validation, I collected all available data for funded and unfunded campaigns that had appeared on the indiegogo platform between 2007 and December 31, 2012. There were a number of salient differences between the variables available in the indiegogo and Kickstarter datasets. First, the indiegogo data did not include beginning and ending dates for each campaign, therefore we do not know the

${ }^{17}$ According to the indiegogo website, "Cause" includes: Animals, Community Education, Environment, Health, Politics, Religion; "Creative" includes: Art, Comic, Dance, Design, Fashion, Film, Gaming, Music, Photography, Theater, Transmedia, Video \& Web, Writing; "Entrepreneurial” includes: Food, Small Business, Sports, and Technology. 
duration for each funding cycle. Second, individual project pages on indiegogo do not provide information about the number of Facebook friends for the project creators; however, they do indicate whether a Facebook page has been established. As with Kickstarter, the number of reward levels and the number of updates were accessible for each project. Also each page makes clear whether the campaign is "fixed" (all-ornothing) or "flexible," signaling to prospective funders whether their contribution to the campaign is irrevocable (i.e., contributions to flexible campaigns are irrevocable, where pledges to fixed campaigns may ultimately be returned if the funding goal is not met).

Descriptive statistics and Pearson correlations are presented in Table 7.8 in the appendix. In our sample, about one-third of all campaigns successfully met or exceeded their funding goal; this compares with the Kickstarter sample, where the rate of success was 0.48 . Also, the data indicate that almost 100 percent $(\mu=0.97)$ of the campaigns chose the "flexible" model, which means that the indiegogo platform received nine percent of the funds raised, but project creators would keep the remainder, regardless of whether they reached their funding goal. Also, somewhat fewer campaigns on indiegogo provided links to project websites $(\mu=0.54)$ than campaigns on $\operatorname{Kickstarter}(\mu=0.61)$.

The logistic regression models are similar to the models for the Kickstarter data in Table 7.3, although some of the variables have been modified to address the particular features of the indiegogo dataset. As before, I have controlled for the log of the size of the goal since we should expect that larger or smaller goals will have a differential effect on funding outcomes; smaller goals will be easier to achieve than larger ones. Duration has been omitted as a control variable in this analysis because information about the 
length of a funding campaign was not available. Prior research in venture finance has found that founding team strength has a positive effect on the likelihood of attracting venture capital financing (Gimmon \& Levie, 2010; Hsu, 2007). Therefore, since the indiegogo dataset includes information about the number of team members for each campaign, team strength has been operationalized as the number of people (i.e., team members) associated with each campaign. Also, even though nearly all indiegogo campaigns adopted the flexible funding approach, I used a dummy variable of one if the campaign was flexible and a zero if it was fixed. As before, I have also included a dummy variable to control for the presence or absence of a link to an external website. And, finally, I have controlled for project categories; however, in order to simplify interpretation of the data, rather than include a dummy variable for each of the 24 project categories, I have instead dummy coded for the three "supra-categories" (Cause, Creative, Entrepreneurial) within which all of the individual categories are subsumed.

With respect to the predictor variables, the analysis includes both constructs (i.e., selective incentives and social engagement factors), although their operationalization has been modified, but only slightly. Selective incentives are captured, as before, in the number of reward levels for each campaign. However, since indiegogo does not require project creators to offer rewards, I have also included a dummy variable of one if the project offers any reward and a zero if it does not. The purpose for this approach is to test whether the availability of a reward (or lack of one) is a meaningful incentive for prospective backers. This analysis was not possible with the Kickstarter dataset since all projects on that platform offered at least one level of reward. 
Social engagement has been captured, as with the earlier analysis, in the number of updates offered by each campaign. Since the number of Facebook friends for the project creator was not available in the indiegogo dataset, I have dummy coded the availability of a Facebook account as a one, and the lack of an account as a zero. ${ }^{18}$

The results for the bivariate logistic regression of the indiegogo data appear in Table 7.9 in the appendix. Across all four models the effect of goal size was consistent with the findings from the analysis of the Kickstarter data; funding goal size was statistically significant and negatively related to the likelihood that campaign would achieve its goal. Also, as theory predicts, team strength (i.e., number of project team members) had a significant and positive relationship with successful funding outcomes. Model 1, which excludes the predictor variables, indicates that base model explains 32.9 percent of the variance $($ Nagelkerke R-square $=0.329)$ in the outcomes.

Model 2 shows the effect of rewards and reward levels. This model is stronger than Model 1, but it does not have significantly more predictive power than the base model without the selective incentive variables (Nagelkerke R-square $=0.336$ ). Somewhat surprisingly, although the availability of a reward (dummy variable) is statistically significant, it has a negative relationship with successful funding $(\operatorname{Exp}(B)=$ $0.83, \mathrm{p}<0.01$ ). In addition, the individual effect of reward levels, although positive, is only somewhat influential $(\operatorname{Exp}(B)=1.08, \mathrm{p}<0.001)$ on successful funding outcomes. So, in general, the results of Model 2 do not contradict the findings from the Kickstarter

\footnotetext{
${ }^{18}$ As noted for the earlier analysis of the Kickstarter data, some indiegogo campaigns provide a link to a personal Facebook account page for the project creator, whereas others link to a dedicated project or company page on Facebook; these distinctions were not coded for this analysis.
} 
data, but they are only modestly supportive. Model 3 isolates the effect of the social engagement factors on funding success. The number of updates had a statistically significant but negligible influence on funding $(\operatorname{Exp}(B)=0.00, \mathrm{p}<0.001)$; the presence of a Facebook account was not significant. Model 4 had the best fit to the data, explaining 34.6 percent of variability in the outcome $($ Nagelkerke R-square $=0.346)$, but this was still only moderately better than the base model. In this model the number of reward levels and the number of updates were statistically significant and weakly related to successful funding $(\operatorname{Reward~levels,~} \operatorname{Exp}(B)=1.07, \mathrm{p}<0.001 ; \operatorname{Updates},(\operatorname{Exp}(B)=1.03, \mathrm{p}$ $<0.001)$. 


\section{Discussion}

This study started with the premise that reward-based crowdfunding can best be explained by a private-collective theory of innovation, whereby selective incentives and other nontangible, socially-motivated factors account for funding outcomes. Since both the qualitative evidence and the results from the quantitative analysis showed that both of the main constructs were important, there is general support for the premise of this dissertation.

The results also suggest that previous organizational theoretic explanations for the role of social factors, such as network ties and social capital, in the financing of innovation and entrepreneurship have been too narrowly defined. Prior literature on this subject has discussed social factors as a mechanism for mitigating information asymmetries between entrepreneurs or innovators and prospective funders; i.e., social ties transfer private information or heighten norms of obligation in ways that heighten trust and facilitate financing commitments (e.g., Shane et al., 2002; Stuart et al., 2005, 2007). However, in the present study the data suggest a complementary, but alternative view: funders seek social engagement not for private information or trust, but because they place intrinsic value on being "involved" with a project, idea, venture, person. The results showed that even when tangible rewards are available, funders' responsiveness to updates from projects creators dominates, even when controlling for a broad range of other potential motivating factors (e.g., funding goal size, project category, project quality, etc.). This effect was consistent throughout the analysis, suggesting that prior theory may 
be overly parsimonious and under-socialized. This is significant because it heightens our understanding of the role of community, affinity, participation and joining in the process of innovation (von Krogh, Spaeth, \& Lakhani, 2003). Moreover, it suggests that an incentive for investing in innovation or entrepreneurship is the "insider status" that comes with participation.

\subsection{Limitations}

This study has a number of limitations. First, it was assumed that the number of reward levels would be a sufficient proxy for tangible incentives. This assumption was tenable because projects that offer numerous reward levels are presenting potential funders with multiple opportunities (with associated tangible perks or rewards) to contribute to the project. However, this measure does not tell us qualitatively how valuable or how motivating any of those rewards or perks may have been. For instance, a project with just one reward level that delivers the actual crowdfunded product may be a more powerful incentive than a project with many reward levels that doesn't deliver a crowdfunded product at all (i.e., only tokens gifts are delivered). Therefore, future research that investigates the relative quality and desirability of incentives will offer a better test of the hypothesis regarding the importance of tangible rewards and selective incentives. The results in this study found that tangible rewards had a modest effect on funding outcomes, but if we could control for their relative quality/desirability, then it may give this construct more explanatory power than it currently offers. 
Second, there could be an endogeneity problem from using the number of updates as an indicator for the social-engagement construct. In my analysis I have assumed that the number of updates provided by a project creator is independent from the funding outcome. This is plausible since the qualitative evidence from the interviews shows that entrepreneurs who ran successful campaigns had made a deliberate choice ex ante to communicate regularly with the crowdfunding community. They explained that this approach enhanced their credibility and improved their likelihood of attracting attention. However, it is also entirely possible that certain campaigns became successful and attracted attention for reasons unrelated to the responsiveness or communicativeness of the project creator; thus, the number of updates may instead have been only a consequence of the amount of attention that was coming to the project for other unobservable reasons. For instance, the project creator may have been providing more updates in response to the funding activity, and not the other way around. Therefore, a possible solution to this problem would be to acquire longitudinal, time-series data (e.g., funding and update data on a daily basis) for the duration of each campaign. In this way it would be possible to assess more precisely whether the update traffic was influencing the funding activity, or vice versa.

Third, this study examined only the factors influencing funding outcomes on a reward-based crowdfunding platform. Consequently we can only generalize the effects of incentives and rewards to similar non-financial funding environments. Some early evidence suggests that these factors are also relevant in the context of debt-based (i.e., peer-to-peer lending) crowdfunding platforms (Freedman et al., 2008), but future 
research is necessary to assess their importance in the newly emerging arena of equitybased crowdfunding (Ahlers, Cumming, Günther, \& Schweizer, 2012).

\section{$5.2 \quad$ Future directions}

Crowdfunding offers many rich opportunities for understanding a wide range of social phenomena related to innovation, entrepreneurship, and venture finance. Future research may include new approaches, including experiments, field studies, and further quantitative analyses of the drivers of voluntary behavior and the mechanisms that affect the collective evaluation process. In this section, I offer a few promising areas for further study and analysis.

\section{Performance outcomes}

Creating new sources of capital and ensuring widespread access to capital is important, but the significance of crowdfunding will ultimately depend on how well crowdfunded ideas, projects, and ventures actually perform relative to ideas, projects, and ventures that are capitalized in some other way. This dissertation examined only project funding as the dependent variable; future research should assess the potential impact of crowdfunding on actual post-funding performance outcomes. Do firms or projects that are funded through a crowdfunding platform perform better, worse, or just differently from those that do not? Are there differential performance effects across the types of crowdfunding platforms (i.e., reward-based, peer-to-peer lending, equity-based)? A longterm, longitudinal study within and across categories of successfully funded projects 
would be an important contribution to our understanding of the crowdfunding phenomenon. ${ }^{19}$

In addition to project performance, we should also like to know if crowdfunding is creating new and different forms of innovation. Is there something about the collective funding process that results in fundamentally new ideas, products, and services?

For me, the key context for Kickstarter's success is this: If Kickstarter merely funds things that would have gotten money in some other way, it's a cool thing. But, if Kickstarter funding allows the creation of fundamentally new and different kinds of stuff, then it is a creative engine of a much-higher caliber (Madrigal, 2012).

In other words, is crowdfunding substituting for other sources of capital? Or is it s complement of forms of capital, one that brings additional, creative, collective benefits to innovation that we have not seen before?

One fruitful direction for the exploration of these questions would be an examination of crowdfunded films, as merely one example. On Kickstarter films are the dominant project category: $28 \%$ of all campaigns are film projects. On indiegogo, originally established to support independent filmmakers, $47 \%$ of all campaigns are for films. The importance of crowdfunding for film is further reflected in the set of projects that ultimately receive funding: $26 \%$ of all funded projects on Kickstarter are films; $30 \%$

\footnotetext{
${ }^{19}$ Mollick (2012) addressed the question of whether successful crowdfunding leads to the successful development of goods and service. Using 471 successfully funded Kickstarter projects in the Technology and Design categories, he coded each to determine if and when they had delivered promised products and rewards. From the 316 that promised to deliver actual products (i.e., not merely tokens), 14 failed to deliver; 247 projects actually delivered goods, and the mean delay was 1.28 months $(\mathrm{sd}=1.56)$. Only 24.9 percent delivered their products on time. Further research in this direction could seek to identify matched pairs of projects, both with crowdfunding and external to it, in order to evaluate performance.
} 
of all funded projects on indiegogo are also films. These figures dwarf nearly every other project category, except possibly music (see Table 7.1 in the appendix). As of December 31, 2012, \$100 million had been pledged for independent film projects on Kickstarter.

Recently Kickstarter has begun to offer data on the performance of these projects in terms of their production, distribution, exhibition (i.e., prestigious film festivals), and recognition (e.g., Academy Awards). Using this category for projects alone, future research could explore the extent to which crowdfunding was or was not a contributing factor to any of these or other performance effect, including whether these film projects are substantially different from projects that would be funded in some other way.

\section{Geographic patterns}

Future study of crowdfunding also offers an opportunity to deepen our knowledge about the geographic patterns of innovation and venture finance. Prior work has already established the important role of geographic proximity in the financing of innovation and entrepreneurship (Lerner, 1995; Sorenson \& Stuart, 2001; Stuart et al., 2005). Today various synchronous communications through Internet-enabled technologies, such as social media, may make entrepreneurs less limited by their geographical locations, possibly developing ties with geographically distant organizations and resources (Cooper, 2002; Sorenson, 2003). Crowdfunding presents a research context in which geographic data for project creators and their funders is readily available; therefore further work on this subject would be fruitful for understanding whether crowdfunding changes the importance of location for funding and performance outcomes. 
A few scholars have begun to explore these questions. In an analysis of crowdfunded music projects on the Sellaband platform, Agrawal, Catalini and Goldfarb (2011) found that the average distance between project funders and project sponsors was about $5,000 \mathrm{~km}$. This finding would seem to indicate that, at least in the context of crowdfunding, geographic proximity between investors and entrepreneurs hardly matters, dispelling the conventional wisdom that investors prefer to be close to their investments in order to monitor them; this is evidenced by traditional venture capitalists, whose average distance from their target firms is approximately $112 \mathrm{~km}$. However, each fundraising campaign on Sellaband has a final target of $\$ 50,000$, and the authors found that local investors are more likely to account for the first $\$ 20,000$ raised, only later to be followed by more distant investors. We should therefore expect that geographically proximate ties will be more significant than more distant ones early in the funding effort, in terms of achieving overall funding goals. In fact, Agrawal, Catalini and Goldfarb (2011) found that investors' propensity to invest in general increases and accelerates as projects visibly accumulate capital on a crowdfunding platform, lending credence to the hypothesis that early commitments from strong, proximate network ties predetermine eventual funding success.

\section{New venture legitimacy}

This study also suggests an important avenue for research on new venture legitimacy. Contributing to the information asymmetry problem for new projects or ventures is the extent to which it is also perceived as having (or lacking) legitimacy. Legitimacy refers to the "perception or assumption that the actions of an entity are 
desirable, proper, or appropriate within some socially constructed system of norms, values, beliefs, and definitions" (Suchman, 1995, p.574). New ventures, especially those in the earliest stages of development, may not be perceived as having these qualities or characteristics simply because of their newness. Therefore, if a venture is not considered to be acceptable, appropriate, or desirable, it may have difficulty attracting the resources it needs to grow (Zimmerman \& Zeitz, 2002). Thus, a perceived lack of legitimacy exacerbates its liability of newness, raising further doubts about its viability and threatening its survival and growth (Aldrich \& Auster, 1986; Stinchcombe, 1965).

The results of this study suggest that projects or firms that effectively signal the value of their intangible resources, such as social capital (e.g., social engagement, network ties) are more likely to attract funders and customers. Moreover, the qualitative evidence from the interviews in this study indicated that the very act of affiliating with a crowdfunding platform enhanced (or even established) their legitimacy, resulting in favorable funding outcomes. Therefore, future work should explore the legitimacyconferring aspect of crowdfunding platforms and the extent to which the platform itself, such as we see with prominent venture-capital-firm-affiliations, confers meaningful legitimacy on the projects seeking funding and support (Busenitz, Fiet, \& Moesel, 2004; Hsu, 2004; Stuart, Hoang, \& Hybels, 1999).

\section{Social information effects}

Finally this study suggests a future direction for research examining the effect of social information on individual decision-making, especially under conditions of uncertainty. "[W]hen people are uncertain, they look to the actions of others to guide 
their actions" (Cialdini, 1993, p. 154). In the context of public goods and charitable giving, two sets of theoretical models purport to explain the relationship between others' actions and one's own. One model suggests that others' contributions will be negatively related to one's own, largely a result of a substitution, or "crowding-out," effect, on the assumption that the public good will be provided without their later-stage participation (e.g., Andreoni, 1990). The other model predicts the opposite effect, where one's contributions will be complementary to those of others, motivated by reciprocity (Sugden, 1984), conformity (Bernheim, 1994), or signals of quality (Vesterlund, 2003). There is a growing body of literature on this question, but the results are inconclusive (Croson \& Shang, 2008; Frey \& Meier, 2004; Shang \& Croson, 2009).

Crowdfunding offers a novel empirical domain in which to further test the foregoing theories. Not only is crowdfunding built upon the model of a social networking platform, making social information especially salient to decision makers, but we also found in this study that social factors are a significant predictor of funding outcomes. Moreover, crowdfunding platforms are substantially transparent, sequential-decisionmaking, "repeated game" (versus “one-shot game") environments; contributors may give to a project one or more times during the duration of a funding campaign. Since rewardbased crowdfunding shares many features of collective-action and public goods problems, future research, perhaps using field experiments with actual crowdfunding campaigns could be particularly fruitful. 


\subsection{Conclusion}

Given the importance of innovation and new venture creation for economic growth and social progress, an understanding of the evolution of the financing mechanisms available for pursuing entrepreneurial opportunities is of vital interest to scholars, policymakers, educators, and practitioners. The main contribution of this paper is straightforward: social factors are a significant influence on the funding outcomes for creative ideas and projects, even more so than other, more tangible incentives. This paper also makes a more foundational contribution by laying the groundwork for further work on the still-emerging domain of crowdfunding. Certainly any research about this subject in this still-developing field is exploratory. Nonetheless, as crowdfunding matures and as the regulatory regimes in the United States and elsewhere continue to adapt to the disruption and disintermediation brought about by this new phenomenon, we should expect this work to be among the first in a very long stream of scholarship on this important and consequential topic. 


\section{REFERENCES}

Agrawal, A., Catalini, C., \& Goldfarb, A. 2011. Friends, Family and the Flat World: The Geography of Crowdfunding, National Bureau of Economic Research Working Paper Series: National Bureau of Economic Research.

Ahlers, G. K. C., Cumming, D., Günther, C., \& Schweizer, D. 2012. Signaling in Equity Crowdfunding, Working Paper Series.

Aldrich, H., \& Auster, E. R. 1986. Even dwarfs started small: Liabilities of age and size and their strategic implications. Research in Organizational Behavior, 8: 165198.

Aldrich, H., \& Zimmer, C. 1986. Entrepreneurship Through Social Networks. In D. L. Sexton, \& R. Smilor, W. (Eds.), The Art and Science of Entrepreneurship: 3-23. Cambridge, MA: Ballinger Publishing Company.

Aldrich, H. E., \& Kim, P. H. 2007. Small worlds, infinite possibilities? How social networks affect entrepreneurial team formation and search. Strategic Entrepreneurship Journal, 1(1-2): 147-165.

Amit, R., Brander, J., \& Zott, C. 1998. Why do venture capital firms exist? Theory and Canadian evidence. Journal of Business Venturing, 13(6): 441-466.

Andreoni, J. 1988. Privately provided public goods in a large economy: The limits of altruism. Journal of Public Economics, 35(1): 57-73.

Andreoni, J. 1990. Impure Altruism and Donations to Public Goods: A Theory of WarmGlow Giving. The Economic Journal, 100(401): 464-477.

Baron, R. A. 2002. OB and entrepreneurship: The reciprocal benefits of closer conceptual links. Research in Organizational Behavior, 24: 225-269.

Belleflamme, P., Lambert, T., \& Schwienbacher, A. 2010. Crowdfunding: An Industrial Organization Perspective. Louvain-le-Neuve, Belgium: Louvain School of Management. 
Bernardo, A. E., \& Welch, I. 2001. On the Evolution of Overconfidence and Entrepreneurs. Journal of Economics \& Management Strategy, 10(3): 301-330.

Bernheim, B. D. 1994. A Theory of Conformity. Journal of Political Economy, 102(5): 841-877.

Bradford, C. S. 2012. Crowdfunding and the Federal Securities Laws. Columbia Business Law Review, 2012(1): 1-150.

Busenitz, L. W., Fiet, J. O., \& Moesel, D. D. 2004. Reconsidering the venture capitalists' "value added" proposition: An interorganizational learning perspective. Journal of Business Venturing, 19(6): 787-807.

Cassar, G. 2004. The financing of business start-ups. Journal of Business Venturing, 19(2): 261-283.

Chen, X.-P., Yao, X., \& Kotha, S. 2009. Entrepreneur Passion And Preparedness In Business Plan Presentations: A Persuasion Analysis Of Venture Capitalists' Funding Decisions. Academy of Management Journal, 52(1): 199-214.

Cialdini, R. B. 1993. Influence: The Psychology of Persuasion. New York: William Morrow \& Company, Inc.

Cooper, A. C. 2002. Networks, Alliances, and Entrepreneurship. In M. A. Hitt, R. D. Ireland, S. M. Camp, \& D. L. Sexton (Eds.), Strategic Entrepreneurship: Creating a New Mindset: 203-222. Oxford, UK: Blackwell Publishers.

Croson, R., \& Shang, J. 2008. The impact of downward social information onÂ contribution decisions. Experimental Economics, 11(3): 221-233.

Crowdsourcing. 2013. 2013CF: The Crowdfunding Industry Report. In C. Esposti, \& K. Berg Kartaszewicz-Grell (Eds.). Los Angeles, CA.

Crowdsourcing, L. 2012. Crowdfunding Industry Report: Market Trends, Composition and Crowdfunding Platforms: massolution. 
Cumming, D. 2006. Adverse Selection and Capital Structure: Evidence from Venture Capital. Entrepreneurship Theory and Practice, 30(2): 155-183.

Delmar, F., \& Shane, S. 2003. Does Business Planning Facilitate the Development of New Ventures? Strategic Management Journal, 24(12): 1165-1185.

Delmar, F. d. r., \& Shane, S. 2004. Legitimating first: organizing activities and the survival of new ventures. Journal of Business Venturing, 19(3): 385-410.

Demsetz, H. 1967. Toward a Theory of Property Rights. The American Economic Review, 57(2): 347-359.

Denis, D. J. 2004. Entrepreneurial finance: an overview of the issues and evidence. Journal of Corporate Finance, 10(2): 301-326.

Edmondson, A. C., \& McManus, S. E. 2007. Methodological Fit in Management Field Research. Academy of Management Review, 32(4): 1155-1179.

Eisenhardt, K. M. 1989. Building Theories from Case Study Research. The Academy of Management Review, 14(4): 532-550.

Freedman, S., \& Jin, G. Z. 2008. Do Social Networks Solve Information Problems for Peer-to-Peer Lending? Evidence from Prosper.com, Indiana University School of Public \& Environmental Affairs Research Paper. Bloomington, IN: Indiana University.

Frey, B. S., \& Meier, S. 2004. Social Comparisons and Pro-Social Behavior: Testing "Conditional Cooperation" in a Field Experiment. The American Economic Review, 94(5): 1717-1722.

Gimmon, E., \& Levie, J. 2010. Founder's human capital, external investment, and the survival of new high-technology ventures. Research Policy, 39(9): 1214-1226.

Gompers, P., \& Lerner, J. 2001. The Venture Capital Revolution. The Journal of Economic Perspectives, 15(2): 145-168. 
Granovetter, M. 1985. Economic Action and Social Structure: The Problem of Embeddedness. American Journal of Sociology, 91(3): 481-510.

Haar, N. E., Starr, J., \& MacMillan, I. C. 1988. Informal risk capital investors: Investment patterns on the East Coast of the U.S.A. Journal of Business Venturing, 3(1): 11-29.

Hoang, H., \& Antoncic, B. 2003. Network-based research in entrepreneurship: A critical review. Journal of Business Venturing, 18(2): 165-187.

Hsu, D. H. 2004. What Do Entrepreneurs Pay for Venture Capital Affiliation? The Journal of Finance, 59(4): 1805-1844.

Hsu, D. H. 2007. Experienced entrepreneurial founders, organizational capital, and venture capital funding. Research Policy, 36(5): 722-741.

Jeppesen, L. B., \& Frederiksen, L. 2006. Why Do Users Contribute to Firm-Hosted User Communities? The Case of Computer-Controlled Music Instruments. Organization Science, 17(1): 45-63.

Johannison, B. 2000. Networking and Entrepreneurial Growth. In D. L. Sexton, \& H. Landstrom (Eds.), The Blackwell Handbook of Entrepreneurship: 368-386. Malden, MA: Blackwell Publishers Inc.

Kaplan, S. N., \& Stromberg, P. 2003. Financial Contracting Theory Meets the Real World: An Empirical Analysis of Venture Capital Contracts. The Review of Economic Studies, 70(2): 281-315.

Khaire, M. 2012. Young and No Money? Never Mind: The Material Impact of Social Resources on New Venture Growth. Organization Science, 21(1): 168-185.

Kleemann, F., Voss, G. G., \& Rieder, K. 2008. Un(der)paid Innovators: The Commercial Utiliza-tion of Consumer Work through Crowdsourcing. Science, Technology \& Innovation Studies, 4(1): 5-26. 
Kuppuswamy, V., \& Bayus, B. L. 2013. Crowdfunding Creative Ideas: The Dynamics of Project Backers in Kickstarter. Chapel Hill, NC: Kenan-Flagler Business School, University of North Carolina.

Larson, A., \& Starr, J. A. 1993. A Network Model of Organization Formation.

Entrepreneurship: Theory \& Practice, 17(2): 5-15.

Lerner, J. 1995. Venture Capitalists and the Oversight of Private Firms. Journal of Finance, 50(1): 301-318.

Lerner, J., \& Tirole, J. 2002. Some Simple Economics of Open Source. The Journal of Industrial Economics, 50(2): 197-234.

Lerner, J., \& Tirole, J. 2005. The Economics of Technology Sharing: Open Source and Beyond. The Journal of Economic Perspectives, 19(2): 99-120.

Lin, M., Prabhala, N. R., \& Viswanathan, S. 2011. Judging Borrowers by the Company They Keep: Friendship Networks and Information Asymmetry in Online Peer-toPeer Lending.

Madrigal, A. C. 2012. Until Yesterday, Kickstarter Had No \$1 Million Projects-Today, It Has 2, The Atlantic.

Mollick, E. 2012. The Dynamics of Crowdfunding: Determinants of Success and Failure, Working Papers Series: July 11, 2012. Philadelphia, PA: The Wharton School of the University of Pennsylvania.

Oliver, P. 1980. Rewards and Punishments as Selective Incentives for Collective Action: Theoretical Investigations. American Journal of Sociology, 85(6): 1356-1375.

Olson, M. 1965. The Logic of Collective Action: Public Goods and the Theory of Groups. Cambridge, MA: Harvard University Press.

Roberts, J. A., Hann, I.-H., \& Slaughter, S. A. 2006. Understanding the Motivations, Participation, and Performance of Open Source Software Developers: A 
Longitudinal Study of the Apache Projects. Management Science, 52(7): 984999.

Samuelson, P. A. 1954. The Pure Theory of Public Expenditure. The Review of Economics and Statistics, 36(4): 387-389.

Schwienbacher, A., \& Larralde, B. 2012. Crowdfunding of Entrepreneurial Ventures. In C. Douglas (Ed.), The Oxford Handbook of Entrepreneurial Finance: 369-391. New York: Oxford University Press.

Scire, M. J. 2011. Person-to-Person Lending: New Regulatory Challenges Could Emerge as the Industry Grows. In U. S. G. A. Office (Ed.). Washington, D.C.

Shane, S. 2003. A General Theory of Entrepreneurship: The Individual-Opportunity Nexus. Northampton, MA: Edward Elgar Publishing Inc.

Shane, S., \& Cable, D. 2002. Network Ties, Reputation, and the Financing of New Ventures. Management Science, 48(3): 364-381.

Shang, J., \& Croson, R. 2009. A Field Experiment in Charitable Contribution: The Impact of Social Information on the Voluntary Provision of Public Goods. The Economic Journal, 119(540): 1422-1439.

Simon, M., Houghton, S. M., \& Aquino, K. 2000. Cognitive biases, risk perception, and venture formation: How individuals decide to start companies. Journal of Business Venturing, 15(2): 113-134.

Slotte-Kock, S., \& Coviello, N. 2010. Entrepreneurship Research on Network Processes: A Review and Ways Forward. Entrepreneurship Theory and Practice, 34(1): 31 57.

Sorenson, O. 2003. Social networks and industrial geography. Journal of Evolutionary Economics, 13(5): 513-527. 
Sorenson, O., \& Stuart, TobyÂ E. 2001. Syndication Networks and the Spatial Distribution of Venture Capital Investments. American Journal of Sociology, 106(6): 1546-1588.

Starr, J. A., \& MacMillan, I. C. 1990. Resource Cooptation Via Social Contracting: Resource Acquisition Strategies for New Ventures. Strategic Management Journal, 11: 79-92.

Stinchcombe, A. L. 1965. Social structure and organizations. In J. G. March (Ed.), Handbook of Organizations: 142-193. Chicago: Rand-McNally.

Stuart, T. E., Hoang, H., \& Hybels, R. C. 1999. Interorganizational Endorsements and the Performance of Entrepreneurial Ventures. Administrative Science Quarterly, 44(2): 315-349.

Stuart, T. E., \& Sorenson, O. 2005. Social Networks and Entrepreneurship. In S. A. Alvarez (Ed.), Handbook of Entrepreneurship Research: Disciplinary Perspectives: 211-228. New York: Springer.

Stuart, T. E., \& Sorenson, O. 2007. Strategic networks and entrepreneurial ventures. Strategic Entrepreneurship Journal, 1(3-4): 211-227.

Suchman, M. C. 1995. Managing Legitimacy: Strategic and Institutional Approaches. The Academy of Management Review, 20(3): 571-610.

Sugden, R. 1984. Reciprocity: The Supply of Public Goods Through Voluntary Contributions. The Economic Journal, 94(376): 772-787.

Tyebjee, T. T., \& Bruno, A. V. 1984. A Model of Venture Capitalist Investment Activity. Management Science, 30(9): 1051-1066.

Uzzi, B. 1997. Social Structure and Competition in Interfirm Networks: The Paradox of Embeddedness. Administrative Science Quarterly, 42(1): 35-67. 
Uzzi, B. 1999. Embeddedness in the Making of Financial Capital: How Social Relations and Networks Benefit Firms Seeking Financing. American Sociological Review, 64(4): 481-505.

Venkataraman, S. 1997. The distinctive domain of entrepreneurship research: An editor's perspective. In J. Katz, \& R. Brokhous (Eds.), Advances in

Entrepreneurship, Firm Emergence, and Growth, Vol. 3. Greenwich: JAI Press.

Vesterlund, L. 2003. The informational value of sequential fundraising. Journal of Public Economics, 87(3â€“44): 627-657.

von Hippel, E., \& von Krogh, G. 2003. Open Source Software and the "PrivateCollective" Innovation Model: Issues for Organization Science. Organization Science, 14(2): 209-223.

von Krogh, G., Spaeth, S., \& Lakhani, K. R. 2003. Community, joining, and specialization in open source software innovation: a case study. Research Policy, 32(7): 1217-1241.

von Krogh, G., \& von Hippel, E. 2006. The Promise of Research on Open Source Software. Management Science, 52(7): 975-983.

Wetzel, W. E. 1987. The informal venture capital market: Aspects of scale and market efficiency. Journal of Business Venturing, 2(4): 299-313.

Williamson, O. E. 1993. Opportunism and its Critics. Managerial \& Decision Economics, 14(2): 97-107.

Yin, R. K. 2003. Case Study Research: Design and Methods (3rd ed.). Thousand Oaks, CA: SAGE Publications.

Zimmerman, M. A., \& Zeitz, G. J. 2002. Beyond Survival: Achieving New Venture Growth by Building Legitimacy. The Academy of Management Review, 27(3): 414-431. 


\section{APPENDiX A: TABLES}

\subsection{Summary of campaign characteristics}

\begin{tabular}{|c|c|c|c|c|c|c|c|c|c|c|c|}
\hline & Projects & $\begin{array}{c}\text { Projects } \\
\text { (percent) }\end{array}$ & $\begin{array}{l}\text { Projects } \\
\text { Funded }\end{array}$ & $\begin{array}{c}\text { Projects } \\
\text { Funded } \\
\text { (percent) }\end{array}$ & Goal Size & $\begin{array}{l}\text { Amount } \\
\text { Funded }\end{array}$ & Funders & $\begin{array}{c}\text { Duration } \\
\text { (Days) }\end{array}$ & Updates & Comments & Rewards \\
\hline Overall & 71,304 & 1.00 & 34,262 & 0.48 & $\begin{array}{c}\mathbf{\$ 1 3 , 9 3 0} \\
(\$ 195,152)\end{array}$ & $\begin{array}{c}\mathbf{\$ 6 , 0 1 2} \\
(\$ 65,413)\end{array}$ & $\begin{array}{c}\mathbf{8 1} \\
(682)\end{array}$ & $\begin{array}{c}37.5 \\
(16.3)\end{array}$ & $\begin{array}{c}\mathbf{4 . 4} \\
(7.1)\end{array}$ & $\begin{array}{c}\mathbf{1 5 . 1} \\
(457.3)\end{array}$ & $\begin{array}{c}8.2 \\
(4.7)\end{array}$ \\
\hline Funded & & & 34,262 & & $\begin{array}{c}\mathbf{\$ 6 , 6 0 3} \\
(\$ 19,556)\end{array}$ & $\begin{array}{c}\mathbf{\$ 1 1 , 2 5 4} \\
(\$ 93,954)\end{array}$ & $\begin{array}{c}\mathbf{1 5 0} \\
(977.7)\end{array}$ & $\begin{array}{c}35.3 \\
(15.2)\end{array}$ & $\begin{array}{c}7.5 \\
(8.7)\end{array}$ & $\begin{array}{c}\mathbf{2 9 . 9 2} \\
(659.3)\end{array}$ & $\begin{array}{c}\mathbf{9 . 0} \\
(5.1)\end{array}$ \\
\hline Unfunded & & & 37,042 & & $\begin{array}{c}\$ \mathbf{2 0 , 7 0 8} \\
(\$ 269,929)\end{array}$ & $\begin{array}{l}\$ 1,163 \\
(\$ 4,799)\end{array}$ & $\begin{array}{c}\mathbf{1 6} \\
(59.5)\end{array}$ & $\begin{array}{c}39.5 \\
(17.1)\end{array}$ & $\begin{array}{c}\mathbf{1 . 5} \\
(3.3)\end{array}$ & $\begin{array}{c}\mathbf{1 . 4} \\
(15.7)\end{array}$ & $\begin{array}{c}7.6 \\
(4.2)\end{array}$ \\
\hline Art & 6,772 & 0.09 & 3,576 & 0.53 & $\begin{array}{c}\mathbf{\$ 8 , 0 3 0} \\
(\$ 37,064)\end{array}$ & $\begin{array}{c}\$ 3,233 \\
(\$ 13,576)\end{array}$ & $\begin{array}{c}52 \\
(262)\end{array}$ & $\begin{array}{c}35.2 \\
(16.3)\end{array}$ & $\begin{array}{c}4.2 \\
(7.0)\end{array}$ & $\begin{array}{c}4.9 \\
(102.9)\end{array}$ & $\begin{array}{c}7.5 \\
(4.4)\end{array}$ \\
\hline Comic & 1,836 & 0.03 & 913 & 0.50 & $\begin{array}{c}\$ 7,326 \\
(\$ 16,865)\end{array}$ & $\begin{array}{c}\mathbf{\$ 6 , 0 8 8} \\
(\$ 35,091)\end{array}$ & $\begin{array}{c}\mathbf{1 1 6} \\
(504)\end{array}$ & $\begin{array}{c}39.4 \\
(16.4)\end{array}$ & $\begin{array}{c}7.8 \\
(10.2)\end{array}$ & $\begin{array}{c}\mathbf{2 5 . 9} \\
(503.0)\end{array}$ & $\begin{array}{l}\mathbf{1 0 . 2} \\
(7.4)\end{array}$ \\
\hline Dance & 1,029 & 0.01 & 759 & 0.74 & $\begin{array}{c}\mathbf{\$ 6 , 1 2 9} \\
(\$ 40,297)\end{array}$ & $\begin{array}{c}\$ 3,057 \\
(\$ 3,679)\end{array}$ & $\begin{array}{c}43 \\
(45)\end{array}$ & $\begin{array}{c}\mathbf{3 5 . 1} \\
(15.2)\end{array}$ & $\begin{array}{c}3.2 \\
(4.1)\end{array}$ & $\begin{array}{c}\mathbf{1 . 4} \\
(3.1)\end{array}$ & $\begin{array}{c}\mathbf{6 . 8} \\
(3.2)\end{array}$ \\
\hline Design & 2,247 & 0.03 & 934 & 0.42 & $\begin{array}{c}\mathbf{\$ 2 2 , 8 9 6} \\
(\$ 50,139)\end{array}$ & $\begin{array}{c}\mathbf{\$ 2 5 , 4 5 9} \\
(\$ 227,713)\end{array}$ & $\begin{array}{c}287 \\
(1651)\end{array}$ & $\begin{array}{c}\mathbf{3 7 . 1} \\
(13.6)\end{array}$ & $\begin{array}{c}\mathbf{6 . 8} \\
(9.1)\end{array}$ & $\begin{array}{c}\mathbf{4 7 . 1} \\
(78.6)\end{array}$ & $\begin{array}{c}8.5 \\
(4.4)\end{array}$ \\
\hline Fashion & 2,107 & 0.03 & 647 & 0.31 & $\begin{array}{c}\mathbf{\$ 9 , 0 1 8} \\
(\$ 20,807)\end{array}$ & $\begin{array}{c}\$ \mathbf{3 , 8 6 4} \\
(\$ 16,975)\end{array}$ & $\begin{array}{c}53 \\
(274)\end{array}$ & $\begin{array}{c}34.5 \\
(15.7)\end{array}$ & $\begin{array}{c}3.0 \\
(4.9)\end{array}$ & $\begin{array}{c}5.3 \\
(30.6)\end{array}$ & $\begin{array}{c}\mathbf{8 . 0} \\
(4.1)\end{array}$ \\
\hline Film \& Video & 19,329 & 0.27 & 8,512 & 0.44 & $\begin{array}{c}\$ \mathbf{2 1 1 , 7 3 8} \\
(\$ 294,776)\end{array}$ & $\begin{array}{c}\$ \mathbf{5 , 1 4 7} \\
(\$ 14,833)\end{array}$ & $\begin{array}{c}57 \\
(201)\end{array}$ & $\begin{array}{c}\mathbf{3 9 . 0} \\
(17.3)\end{array}$ & $\begin{array}{c}4.3 \\
(7.0)\end{array}$ & $\begin{array}{c}3.6 \\
(23.7)\end{array}$ & $\begin{array}{c}8.3 \\
(4.5)\end{array}$ \\
\hline Food & 2,466 & 0.03 & 1,048 & 0.42 & $\begin{array}{c}\$ \mathbf{1 6 , 2 5 4} \\
(\$ 74,169)\end{array}$ & $\begin{array}{c}\mathbf{\$ 5 , 9 9 5} \\
(\$ 16,718)\end{array}$ & $\begin{array}{c}73 \\
(155)\end{array}$ & $\begin{array}{c}36.3 \\
(14.5)\end{array}$ & $\begin{array}{c}\mathbf{4 . 3} \\
(5.9)\end{array}$ & $\begin{array}{c}\mathbf{5 . 6} \\
(2.0)\end{array}$ & $\begin{array}{c}8.7 \\
(4.9)\end{array}$ \\
\hline Games & 3,210 & 0.05 & 1,242 & 0.39 & $\begin{array}{c}\mathbf{\$ 2 7 , 8 6 1} \\
(\$ 84,817)\end{array}$ & $\begin{array}{c}\mathbf{\$ 2 4 , 3 8 2} \\
(\$ 216,794)\end{array}$ & $\begin{array}{c}382 \\
(2636)\end{array}$ & $\begin{array}{c}\mathbf{3 6 . 0} \\
(13.6)\end{array}$ & $\begin{array}{c}\mathbf{9 . 2} \\
(12.5)\end{array}$ & $\begin{array}{c}\mathbf{1 9 9 . 8} \\
(2090.2)\end{array}$ & $\begin{array}{c}\mathbf{9 . 9} \\
(5.8)\end{array}$ \\
\hline Music & 17,611 & 0.25 & 10,229 & 0.58 & $\begin{array}{c}\$ \mathbf{8 7 , 6 9 1} \\
(\$ 163,748)\end{array}$ & $\begin{array}{c}\mathbf{\$ 3 , 6 6 0} \\
(\$ 11,778)\end{array}$ & $\begin{array}{c}\mathbf{5 5} \\
(232)\end{array}$ & $\begin{array}{c}\mathbf{3 8 . 0} \\
(16.2)\end{array}$ & $\begin{array}{c}3.8 \\
(5.4)\end{array}$ & $\begin{array}{c}4.2 \\
(34.0)\end{array}$ & $\begin{array}{c}8.7 \\
(4.8)\end{array}$ \\
\hline Photography & 2,320 & 0.03 & 953 & 0.41 & $\begin{array}{c}\mathbf{\$ 6 , 5 4 7} \\
(\$ 9,859)\end{array}$ & $\begin{array}{c}\$ \mathbf{2 , 7 0 2} \\
(\$ 5,155)\end{array}$ & $\begin{array}{c}38 \\
(72)\end{array}$ & $\begin{array}{c}\mathbf{3 8 . 2} \\
(17.3)\end{array}$ & $\begin{array}{c}\mathbf{4 . 0} \\
(7.3)\end{array}$ & $\begin{array}{c}2.4 \\
(7.8)\end{array}$ & $\begin{array}{c}7.5 \\
(3.6)\end{array}$ \\
\hline Publishing & 7,418 & 0.10 & 2,472 & 0.33 & $\begin{array}{c}\mathbf{\$ 1 1 , 6 9 1} \\
(\$ 257,090)\end{array}$ & $\begin{array}{c}\mathbf{\$ 2 , 4 9 9} \\
(\$ 9,829)\end{array}$ & $\begin{array}{c}44 \\
(226)\end{array}$ & $\begin{array}{c}\mathbf{3 7 . 0} \\
(15.7)\end{array}$ & $\begin{array}{c}3.7 \\
(6.7)\end{array}$ & $\begin{array}{c}2.3 \\
(10.2)\end{array}$ & $\begin{array}{c}7.3 \\
(0.6)\end{array}$ \\
\hline Technology & 1,316 & 0.02 & 510 & 0.39 & $\begin{array}{c}\mathbf{\$ 2 4 , 9 9 8} \\
(\$ 54,473)\end{array}$ & $\begin{array}{c}\$ \mathbf{2 4 4 , 8 4 5} \\
(\$ 131,021)\end{array}$ & $\begin{array}{c}234 \\
(820)\end{array}$ & $\begin{array}{c}\mathbf{3 7 . 8} \\
(15.7)\end{array}$ & $\begin{array}{c}6.3 \\
(8.9)\end{array}$ & $\begin{array}{c}37.7 \\
(173.7)\end{array}$ & $\begin{array}{c}\mathbf{8 . 0} \\
(4.3)\end{array}$ \\
\hline Theater & 3,643 & 0.05 & 2,467 & 0.68 & $\begin{array}{c}\mathbf{\$ 7 , 8 9 4} \\
(\$ 55,578)\end{array}$ & $\begin{array}{c}\mathbf{\$ 3 , 4 5 7} \\
(7837.61)\end{array}$ & $\begin{array}{c}49 \\
(203.0)\end{array}$ & $\begin{array}{c}35.9 \\
(16.6)\end{array}$ & $\begin{array}{c}3.2 \\
(4.7)\end{array}$ & $\begin{array}{c}\mathbf{1 . 7} \\
(9.7)\end{array}$ & $\begin{array}{l}\mathbf{7 . 0} \\
(3.2)\end{array}$ \\
\hline
\end{tabular}




\subsection{Descriptive statistics and correlations: main analysis}

All Kickstarter projects $(N=71,304)$

\begin{tabular}{|c|c|c|c|c|c|c|c|c|c|c|c|c|c|c|c|c|c|c|c|c|c|}
\hline & Mean & $\begin{array}{c}\text { Std. } \\
\text { Dev. }\end{array}$ & 1 & 2 & 3 & 4 & 5 & 6 & 7 & 8 & 9 & 10 & 11 & 12 & 13 & 14 & 15 & 16 & 17 & 18 & 19 \\
\hline 1. Funding Success & 0.48 & 0.50 & 1 & & & & & & & & & & & & & & & & & & \\
\hline 2. Log of Funding Goal & 3.63 & 0.59 & $-.258 * *$ & 1 & & & & & & & & & & & & & & & & & \\
\hline 3. Duration & 37.49 & 16.33 & $-.127 * *$ & $.166^{* *}$ & 1 & & & & & & & & & & & & & & & & \\
\hline 4. Website & 0.61 & 0.49 & $.088 * *$ & $.094 * *$ & $-.030 * *$ & 1 & & & & & & & & & & & & & & & \\
\hline 5. Comic & 0.03 & 0.16 & 0.006 & $-.033^{* *}$ & $.019 * *$ & $.024 * *$ & 1 & & & & & & & & & & & & & & \\
\hline 6. Dance & 0.01 & 0.12 & $.061 * *$ & $-.043^{* *}$ & $-.018^{* *}$ & $.020 * *$ & $-.020 * *$ & 1 & & & & & & & & & & & & & \\
\hline 7. Design & 0.03 & 0.17 & $-.025 * *$ & $.102 * *$ & -0.005 & $.051 * *$ & $-.029 * *$ & $-.022 * *$ & 1 & & & & & & & & & & & & \\
\hline 8. Fashion & 0.03 & 0.17 & $-.058 * *$ & $-.008 *$ & $-.032 * *$ & $.014 * *$ & $-.028 * *$ & $-.021 * *$ & * $-.031 * *$ & $* 1$ & & & & & & & & & & & \\
\hline 9. Film \& Video & 0.27 & 0.44 & $-.049 * *$ & $.143^{* *}$ & $.055^{* *}$ & $-.085^{* *}$ & $*-.099 * *$ & $-.074 * *$ & $-.110 * *$ & $*-.106 * *$ & 1 & & & & & & & & & & \\
\hline 10. Food & 0.03 & 0.18 & $-.020 * *$ & $.081 * *$ & $-.013 * *$ & $.010 * *$ & $-.031 * *$ & $-.023 * *$ & $-.034 * *$ & $*-.033 * *$ & $-.115 * *$ & 1 & & & & & & & & & \\
\hline 11. Games & 0.05 & 0.21 & $-.040 * *$ & $.089 * *$ & $-.020 * *$ & $.058 * *$ & $-.035^{* *}$ & $-.026 * *$ & * $-.039 * *$ & $*-.038 * *$ & $-.132 * *$ & $-.041 * *$ & 1 & & & & & & & & \\
\hline 12. Music & 0.25 & 0.43 & $.114 * *$ & $-.124 * *$ & $.018^{* *}$ & $-.051 * *$ & $*-.093 * *$ & $-.069 * *$ & * $-.103 * *$ & $*-.100 * *$ & $-.349 * *$ & $-.108 * *$ & $-.124 * *$ & 1 & & & & & & & \\
\hline 13. Photography & 0.03 & 0.18 & $-.024 * *$ & $-.032 *$ & $.007 *$ & $.031 * *$ & $-.030 * *$ & $-.022 * *$ & $-.033 * *$ & $*-.032 * *$ & $-.112 * *$ & $-.035 * *$ & $-.040 * *$ & $-.105 * *$ & 1 & & & & & & \\
\hline 14. Publishing & 0.10 & 0.31 & $-.099 * *$ & $-.029 * *$ & $-.011 * *$ & 0.006 & $-.055^{* *}$ & $-.041 * *$ & $*-.061 * *$ & $*-.059 * *$ & $-.208 * *$ & $-.064 * *$ & $-.074 *$ & $-.195 * *$ & $-.062 * *$ & 1 & & & & & \\
\hline 15. Technology & 0.02 & 0.13 & $-.027 * *$ & $.079 * *$ & 0.003 & $.047 * *$ & $-.022 * *$ & $-.017 * *$ & $-.025 * *$ & $*-.024 * *$ & $-.084 * *$ & $-.026 * *$ & $-.030 * *$ & $-.079 * *$ & $-.025 * *$ & $-.047 * *$ & 1 & & & & \\
\hline 16. Theater & 0.05 & 0.22 & $.091 * *$ & $-.064 * *$ & $-.022 * *$ & 0.001 & $-.038 * *$ & $-.028 * *$ & $-.042 * *$ & $*-.040 * *$ & $-.142 * *$ & $-.044 * *$ & $-.050 * *$ & $-.133 * *$ & $-.043 * *$ & $-.079 * *$ & $-.032 * *$ & 1 & & & \\
\hline 17. Rewards & 8.24 & 4.71 & $.150 * *$ & $.291^{* *}$ & 0.006 & $.117 * *$ & $.067 * *$ & $-.038 * *$ & $.008^{*}$ & $-.010 * *$ & 0.004 & $.020 * *$ & $.078^{* *}$ & $.060 * *$ & $-.027 * *$ & $-.067 * *$ & -0.007 & $-.059 * *$ & 1 & & \\
\hline 18. Updates & 4.41 & 7.11 & $.421 * *$ & $.104 * *$ & $.029^{* *}$ & $.137 * *$ & $.077 * *$ & $-.021 * *$ & $.061 * *$ & $-.034 * *$ & $-.012 * *$ & -0.002 & $.146^{* *}$ & $-.048 * *$ & $-.010 * *$ & $-.032 * *$ & $.037 * *$ & $-.039 * *$ & $.301 * *$ & 1 & \\
\hline 19. Facebook Friends & 435.4 & 261.2 & $.234 * *$ & $-.071 * *$ & $.014 *$ & 0.005 & $-.040 * *$ & $.050 * *$ & $-.057 * *$ & $* \mid-.015 *$ & $.060^{* *}$ & $-.047 * *$ & $-.119 * *$ & $.154 * *$ & -0.009 & $-.106 * *$ & $*-.050 * *$ & $* .085^{* *}$ & $.053 * *$ & $.045 * *$ & 1 \\
\hline
\end{tabular}

Key: * $=$ Correlation is significant at the 0.05 level (2-tailed). ${ }^{*}=$ Correlation is significant at the 0.01 level (2-tailed) 


\subsection{Logistic regression: main analysis}

All Kickstarter projects $(N=71,304)$, estimations predicting project funding

\begin{tabular}{|c|c|c|c|c|c|c|c|c|c|c|c|c|}
\hline \multirow{2}{*}{$\begin{array}{l}\text { Variable } \\
\text { CONTROLS }\end{array}$} & \multicolumn{3}{|c|}{ Model 1} & \multicolumn{3}{|c|}{ Model 2} & \multicolumn{3}{|c|}{ Model 3} & \multicolumn{3}{|c|}{ Model 4} \\
\hline & $B$ & (S.E.) & $\operatorname{Exp}(B)$ & $B$ & (S.E.) & $\operatorname{Exp}(B)$ & $B$ & (S.E.) & $\operatorname{Exp}(B)$ & $B$ & (S.E.) & $\overline{\operatorname{Exp}(B)}$ \\
\hline $\log ($ Goal $)$ & -0.93 & $(0.02)$ & $0.39^{* * *}$ & -1.34 & $(0.02)$ & $0.26^{* * *}$ & -1.78 & $-(1.78)$ & $0.17^{* * *}$ & -1.89 & $(0.04)$ & $0.15^{* * *}$ \\
\hline Website & 0.55 & $(0.02)$ & $1.73^{* * *}$ & 0.47 & $(0.02)$ & $1.60^{* * *}$ & 0.27 & $(0.27)$ & $1.30^{* * *}$ & 0.25 & $(0.04)$ & $1.28^{* * *}$ \\
\hline \multicolumn{13}{|l|}{ Category ${ }^{1}$} \\
\hline Comic & 0.03 & $(0.06)$ & 1.03 & -0.29 & $(0.06)$ & $0.75^{* * *}$ & -0.81 & $(0.11)$ & $0.44^{* * *}$ & -0.88 & $(0.12)$ & $0.42^{* * *}$ \\
\hline Design & 0.00 & $(0.05)$ & 1.00 & 0.06 & $(0.05)$ & 1.06 & -0.37 & $(0.11)$ & $0.69^{* *}$ & -0.34 & $(0.11)$ & $0.71^{* *}$ \\
\hline Fashion & -0.77 & $(0.05)$ & $0.46^{* * *}$ & -0.83 & $(0.06)$ & $0.44^{* * *}$ & -0.57 & $(0.10)$ & $0.56^{* * *}$ & -0.58 & $(0.10)$ & $0.56^{* * *}$ \\
\hline Film \& Video & 0.07 & $(0.03)$ & 1.07 & 0.06 & $(0.03)$ & 1.06 & 0.06 & $(0.06)$ & $1.06^{* *}$ & 0.06 & $(0.06)$ & 1.07 \\
\hline Food & 0.05 & $(0.05)$ & 1.05 & 0.04 & $(0.05)$ & 1.04 & 0.29 & $(0.09)$ & 1.34 & 0.29 & $(0.09)$ & $1.33^{* *}$ \\
\hline Games & -0.21 & $(0.05)$ & $0.81^{* * *}$ & -0.41 & $(0.05)$ & $0.67^{* * *}$ & -1.33 & $(0.10)$ & $0.27^{* *}$ & -1.34 & $(0.10)$ & $0.26^{* * *}$ \\
\hline Music & 0.41 & $(0.03)$ & $1.51^{* * *}$ & 0.27 & $(0.03)$ & $1.31^{* * *}$ & 0.33 & $(0.06)$ & $1.40^{* * *}$ & 0.31 & $(0.06)$ & $1.36^{* * *}$ \\
\hline Theater & 0.77 & $(0.04)$ & $2.15^{* * *}$ & 0.86 & $(0.05)$ & $2.36^{* * *}$ & 0.91 & $(0.09)$ & $2.48^{* * *}$ & 0.94 & $(0.09)$ & $2.55^{* * *}$ \\
\hline \multicolumn{13}{|l|}{ PREDICTORS } \\
\hline Rewards & \# & & & 0.14 & $(0.00)$ & $1.15^{* * *}$ & \# & & $* * *$ & 0.04 & $(0.00)$ & $1.04^{* * *}$ \\
\hline Updates & \# & & & \# & & & 0.37 & $(0.01)$ & $1.45^{* * *}$ & 0.36 & $(0.01)$ & $1.44^{* * *}$ \\
\hline Facebook Friends & $\#$ & & & $\#$ & & & 0.00 & $(0.00)$ & 1.00 & 0.00 & $(0.00)$ & $1.00^{* * *}$ \\
\hline Chi-square & & $8,850.8$ & ${ }^{* * *}$ & & $13,235.7$ & ${ }^{* * *}$ & & $14,744.2$ & ${ }^{* * *}$ & & $14,831.8$ & *** \\
\hline Chi-square change & & $\#$ & & & 4384.9 & & & 1508.6 & & & 87.6 & \\
\hline Nagelkerke R Square & & 0.156 & & & 0.226 & & & 0.571 & & & 0.574 & \\
\hline
\end{tabular}




\subsection{Linear regression: main analysis}

All Kickstarter projects $(N=71,304)$, predicting funding relative to campaign goal

Variable
CONTROLS
Log(Goal)
Duration
Website
Category
Comic
Dance
Design
Fashion
Film \& Video
Food
Games
Music
Photography
Publishing
Technology
Theater

\begin{tabular}{ccc}
\multicolumn{3}{c}{ Model 1 } \\
\hline B & (S.E.) & t-stat \\
& & \\
0.72 & $(0.02)$ & $39.82^{* * *}$ \\
-0.01 & $(0.00)$ & $-18.85^{* * *}$ \\
0.90 & $(0.02)$ & $43.00^{* * *}$ \\
& & \\
0.29 & $(0.07)$ & $4.13^{* * *}$ \\
0.86 & $(0.09)$ & $9.57^{* * *}$ \\
0.93 & $(0.07)$ & $13.98^{* * *}$ \\
-0.64 & $(0.07)$ & $-9.48^{* * *}$ \\
-0.03 & $(0.04)$ & -0.78 \\
0.56 & $(0.06)$ & $8.73^{* * *}$ \\
0.33 & $(0.06)$ & $5.71^{* * *}$ \\
0.36 & $(0.04)$ & $9.43^{* * *}$ \\
-0.33 & $(0.06)$ & $-5.12^{* * *}$ \\
-0.89 & $(0.05)$ & $-19.51^{* * *}$ \\
0.50 & $(0.08)$ & $6.08^{* * *}$ \\
0.65 & $(0.06)$ & $11.70^{* * *}$
\end{tabular}

\begin{tabular}{cc} 
Model 2 \\
\hline B $\quad$ (S.E.) t-stat
\end{tabular}

\begin{tabular}{ccc}
\multicolumn{3}{c}{ Model 3} \\
\hline B $\quad$ (S.E.) & t-stat
\end{tabular}

\begin{tabular}{ccc}
\multicolumn{3}{c}{ Model 4 } \\
\hline B & (S.E.) & t-stat \\
& & \\
0.38 & $(0.02)$ & $15.45^{* * *}$ \\
-0.01 & $(0.00)$ & $-14.75^{* * *}$ \\
0.44 & $(0.03)$ & $15.42^{* * *}$ \\
& & \\
-0.35 & $(0.09)$ & $-4.03^{* *}$ \\
0.98 & $(0.12)$ & $7.82^{* * *}$ \\
0.93 & $(0.08)$ & $11.27^{* * *}$ \\
-0.24 & $(0.08)$ & $-2.80^{* * *}$ \\
-0.10 & $(0.05)$ & -2.04 \\
0.76 & $(0.08)$ & $9.86^{* * *}$ \\
-0.19 & $(0.07)$ & -2.68 \\
0.01 & $(0.05)$ & 0.22 \\
-0.23 & $(0.08)$ & -2.74 \\
-0.56 & $(0.06)$ & $-9.77^{* * *}$ \\
0.59 & $(0.10)$ & $5.77^{* * *}$ \\
0.57 & $(0.08)$ & $7.26^{* * *}$
\end{tabular}

\section{PREDICTORS}

$\begin{array}{lc}\text { Rewards } & \# \\ \text { Updates } & \# \\ \text { Facebook Friends } & \#\end{array}$

$\begin{array}{ccc}0.27 & (0.02) & 15.29^{* * *} \\ -0.01 & (0.00) & -16.55^{* * *} \\ 0.74 & (0.02) & 36.83^{* * *} \\ & & \\ -0.19 & (0.07) & -2.75^{* *} \\ 1.01 & (0.09) & 11.79^{* * *} \\ 1.00 & (0.06) & 15.88^{* * *} \\ -0.65 & (0.06) & -10.13^{* * *} \\ -0.05 & (0.04) & -1.40^{* * *} \\ 0.52 & (0.06) & 8.62^{* *} \\ 0.08 & (0.06) & 1.51 \\ 0.14 & (0.04) & 3.88^{* * *} \\ -0.30 & (0.06) & -4.82^{* * *} \\ -0.79 & (0.04) & -18.37^{* * *} \\ 0.65 & (0.08) & 8.42^{* * *} \\ 0.74 & (0.05) & 14.15^{* * *}\end{array}$

$\begin{array}{ccc}-0.23 & (0.00) & -54.03^{* * *} \\ 0.00 & (0.00) & -19.03^{* * *} \\ 0.05 & (0.01) & 10.18^{* * *}\end{array}$

$0.05 \quad(0.01) \quad 10.18^{* * *}$

$\begin{array}{ccc}-0.09 & (0.02) & -5.73^{* * *} \\ 0.21 & (0.02) & 9.46^{* * *}\end{array}$

$0.21 \quad(0.02) \quad 9.46^{* * *}$

$\begin{array}{lll}-0.02 & (0.01) \quad-1.23\end{array}$

$\begin{array}{lll}-0.02 & (0.01) & -1.23 \\ -0.11 & (0.02) & -7.03\end{array}{ }^{* * *}$

$-0.11$

$\begin{array}{lll}0.00 & (0.01) & 0.37 \\ 0.04 & (0.01) & 3.06\end{array}$

$\begin{array}{rrr}0.04 & (0.01) & 3.06 \\ & * * * \\ * * *\end{array}$

0.05

$-0.08$

$\begin{array}{lll}-0.11 \quad(0.01)-10.50^{* *} \\ -0.05 & (0.02) & -2.75\end{array}$

$-0.05 \quad(0.02) \quad-2.75^{* *}$

$0.15 \quad(0.01) \quad 10.20^{* * *}$

$\begin{array}{ccc}0.19 & (0.00) & 87.77^{* * *} \\ \# & & \\ \# & & \\ & & \\ & 864.7^{* * *} \\ & 0.171\end{array}$

$\begin{array}{ccc}\# & \\ 0.03 & (0.00) & 88.78^{* * *} \\ 0.00 & (0.00) & 31.63^{* * *} \\ & \\ & 856.6^{* * *} \\ & 0.355\end{array}$

$\begin{array}{lll}0.11 & (0.00) & 34.63^{* * *} \\ 0.14 & (0.00) & 71.67 \\ 0.00 & (0.00) & 31.37^{* * *} \\ & \\ & 699.3 \\ & \\ & 0.335\end{array}$

$* *=$ Correlation is significant at the $<0.01$ level (2-tailed)

$* * *=$ Correlation is significant at the $<0.001$ level (2-tailed).

${ }^{1}$ Note: The category for "Art" projects is subsumed as a dummy variable in the intercept term. 


\subsection{Descriptive statistics and correlations: internal validation}

Kickstarter technology projects $(N=1,316)$

\begin{tabular}{ll|c|c|c|c|c|c|c|c|c|c|c|c|c|}
\hline & Mean & $\begin{array}{c}\text { Std. } \\
\text { Dev. }\end{array}$ & $\mathbf{1}$ & $\mathbf{2}$ & $\mathbf{3}$ & $\mathbf{4}$ & $\mathbf{5}$ & $\mathbf{6}$ & $\mathbf{7}$ & $\mathbf{8}$ & $\mathbf{9}$ & $\mathbf{1 0}$ & $\mathbf{1 1}$ \\
\hline 1. Funding Success & 0.39 & 0.49 & 1 & & & & & & & & & & \\
2. Log of Funding Goal & 9.16 & 1.46 & $-.231^{* *}$ & 1 & & & & & & & & \\
3. Duration & 37.63 & 15.65 & $-.132^{* *}$ & $.056^{*}$ & 1 & & & & & & & \\
4. Website & 0.78 & 0.41 & $.144^{* *}$ & $.103^{* *}$ & -0.048 & 1 & & & & & & \\
5. Video & 0.84 & 0.37 & $.128^{* *}$ & $.174^{* *}$ & $-.152^{* *}$ & $.132^{* *}$ & 1 & & & & & \\
6. Projects Created & 4.08 & 7.62 & $.178^{* *}$ & 0.002 & $-.138^{* *}$ & $.096^{* *}$ & $.064^{*}$ & 1 & & & & \\
7. Projects Backed & 1.45 & 1.33 & 0.011 & $-.083^{* *}$ & -0.049 & 0.009 & $-.091^{* *}$ & $.145^{* *}$ & 1 & & & \\
8. Product Delivery & 0.66 & 0.47 & 0.052 & $.148^{* *}$ & $-.192^{* *}$ & $.079^{* *}$ & $.181^{* *}$ & $.098^{* *}$ & $-5 \mathrm{E}-05$ & 1 & & \\
9. Rewards & 8.02 & 4.25 & $.204^{* *}$ & $.261^{* *}$ & $-.064^{*}$ & $.159^{* *}$ & $.190^{* *}$ & 0.035 & -0.013 & $.118^{* *}$ & 1 & & \\
10. Updates & 6.41 & 9.00 & $.584^{* *}$ & $.087 * *$ & $-.062^{*}$ & $.162^{* *}$ & $.126^{* *}$ & $.164^{* *}$ & 0.027 & $.111^{* *}$ & $.284^{* *}$ & 1 & \\
11. Facebook Friends & 499.8 & 619.3 & 0.013 & -0.026 & 0.006 & 0.007 & -0.062 & -0.008 & $.155^{* *}$ & $-.096^{*}$ & -0.066 & $-.086^{*}$ & 1 \\
\hline
\end{tabular}

Key: $*=$ Correlation is significant at the 0.05 level (2-tailed). $* *=$ Correlation is significant at the 0.01 level (2-tailed). 


\subsection{Logistic regression: internal validation}

Kickstarter technology projects $(N=1,316)$, predicting project funding

\section{Variable \\ CONTROLS}

\begin{tabular}{lccc} 
& \multicolumn{3}{c}{ Model 1 } \\
\cline { 2 - 4 } $\begin{array}{l}\text { Variable } \\
\text { CONTROLS }\end{array}$ & (S.E.) & $\operatorname{Exp(B)}$ \\
$\quad$ & & & \\
Log(Goal) & -0.44 & $(0.05)$ & $0.64^{* * *}$ \\
Duration & -0.01 & $(0.00)$ & 0.99 \\
Website & 0.83 & $(0.16)$ & $2.30^{* * *}$ \\
Video & 0.89 & $(0.19)$ & $2.44^{* * *}$ \\
Projects Created & 0.05 & $(0.01)$ & $1.05^{* * *}$ \\
Projects Backed & -0.05 & $(0.05)$ & 0.95 \\
Product Delivery & 0.14 & $(0.14)$ & 1.15
\end{tabular}

\section{PREDICTORS}

Rewards

Updates

Facebook Friends

\section{Chi-square}

Chi-square change

Nagelkerke R Square
\#

\begin{tabular}{|c|c|c|}
\hline \multicolumn{3}{|c|}{ Model 2} \\
\hline$B$ & (S.E.) & $\operatorname{Exp}(B)$ \\
\hline-0.60 & $(0.05)$ & $0.55^{* *}$ \\
\hline-0.01 & $(0.00)$ & 0.99 \\
\hline 0.72 & $(0.17)$ & $2.05^{* * *}$ \\
\hline 0.72 & $(0.20)$ & $2.06^{* * *}$ \\
\hline 0.05 & $(0.01)$ & $1.05^{* * *}$ \\
\hline-0.07 & $(0.05)$ & 0.94 \\
\hline 0.08 & $(0.14)$ & 1.08 \\
\hline 0.18 & $(0.02)$ & $1.19^{* * *}$ \\
\hline \# & & \\
\hline \# & & \\
\hline & 287.2 & $* * *$ \\
\hline & 96.1 & \\
\hline & 0.266 & \\
\hline
\end{tabular}

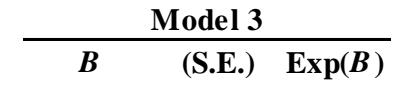

$\begin{array}{lll}-1.02 & (0.12) \quad 0.36^{* * *}\end{array}$

$\begin{array}{lll}0.00 & (0.01) \quad 1.00\end{array}$

$\begin{array}{lll}0.49 & (0.35) \quad 1.63\end{array}$

$\begin{array}{lll}0.48 & (0.38) & 1.62 \\ 0.05 & (0.02) & 1.05\end{array}$ *

$\begin{array}{lll}-0.19 & (0.10) \quad 0.83\end{array}$

$-0.09 \quad(0.29)$

0.91

$\begin{array}{ccc}\# & & \\ 0.40 & (0.03) & 1.49^{* * *} \\ 0.00 & (0.00) & 1.00^{* *}\end{array}$

$456.2^{* * *}$

169.0

0.694
Model 4

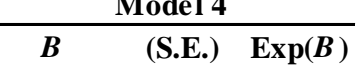

$\begin{array}{ccl}-1.07 & (0.12) & 0.34^{* * *} \\ 0.00 & (0.01) & 1.00 \\ 0.48 & (0.35) & 1.62 \\ 0.48 & (0.38) & 1.62 \\ 0.05 & (0.02) & 1.05 \\ -0.19 & (0.10) & 0.82 \\ -0.12 & (0.30) & 0.89\end{array}$

$\begin{array}{lll}0.06 & (0.04) & 1.06 \\ 0.39 & (0.03) & 1.48^{* * *}\end{array}$

$* *=$ Correlation is significant at the $<0.01$ level (2-tailed).

$* * *=$ Correlation is significant at the $<0.001$ level (2-tailed). 


\subsection{Linear regression: internal validation}

Kickstarter technology projects $(N=1,316)$, predicting project funding relative to campaign goal

\section{Variable CONTROLS}

\begin{tabular}{lccc} 
& \multicolumn{3}{c}{ Model 1 } \\
\cline { 2 - 4 } Variable & $B$ & (S.E.) & t-stat \\
ONTROLS & & & \\
Log(Goal) & -0.36 & $(0.07)$ & $-5.01^{* * *}$ \\
Duration & -0.02 & $(0.01)$ & -2.36 \\
Website & 0.78 & $(0.25)$ & $3.15^{* *}$ \\
Video & 0.52 & $(0.29)$ & 1.83 \\
Projects Created & 0.03 & $(0.01)$ & 1.90 \\
Projects Backed & -0.03 & $(0.08)$ & -0.42 \\
Product Delivery & 0.69 & $(0.22)$ & $3.12^{* *}$
\end{tabular}

\section{PREDICTORS}

Rewards \#

Updates

Facebook Friends

F-statistic

Adjusted R-Square
\#

\#

\#

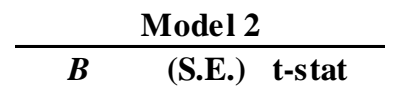

$\begin{array}{lll}-0.45 & (0.07) & -6.14^{* * *} \\ -0.01 & (0.01) & -2.15 \\ 0.62 & (0.25) & 2.53 \\ 0.34 & (0.28) & 1.18 \\ 0.03 & (0.01) & 1.90 \\ -0.04 & (0.08) & -0.50 \\ 0.64 & (0.22) & 2.90^{* *}\end{array}$

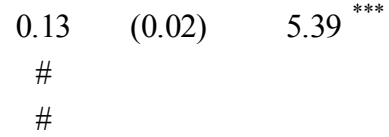

$12.0^{* * *}$

0.063

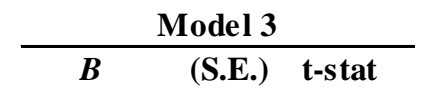

$-0.45 \quad(0.09) \quad-4.74^{* * *}$

$\begin{array}{lll}-0.01 & (0.01) & -1.27\end{array}$

$\begin{array}{lll}0.27 & (0.35) \quad 0.77\end{array}$

$0.28 \quad(0.40) \quad 0.71$

$0.01 \quad(0.01) \quad 0.41$

$\begin{array}{lll}-0.07 \quad(0.08) & -0.85\end{array}$

$0.57 \quad(0.31) \quad 1.84$

$\begin{array}{ccc}\# & & \\ 0.14 & (0.01) & 10.51^{* * *} \\ 0.00 & (0.00) & 0.45\end{array}$

$16.0^{* * *}$

0.176
Model 4

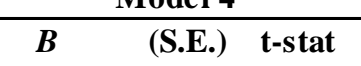

$-0.53 \quad(0.10) \quad-5.48^{* * *}$

$\begin{array}{lll}-0.01 & (0.01) & -1.04\end{array}$

$\begin{array}{lll}0.18 & (0.35) & 0.52\end{array}$

$\begin{array}{lll}0.19 & (0.40) \quad 0.48\end{array}$

$0.01 \quad(0.01) \quad 0.69$

$-0.09 \quad(0.08) \quad-1.12$

$0.46 \quad(0.31) \quad 1.48$

$\begin{array}{lll}0.12 & (0.04) & 3.27^{\text {** }} \\ 0.13 & (0.01) & 9.35^{\text {*** }} \\ 0.00 & (0.00) & 0.59\end{array}$

$* *=$ Correlation is significant at the $<0.01$ level (2-tailed).

$* * *=$ Correlation is significant at the $<0.001$ level (2-tailed). 
All indiegogo projects $(N=22,548)$

\begin{tabular}{|c|c|c|c|c|c|c|c|c|c|c|c|c|c|}
\hline & Mean & $\begin{array}{l}\text { Std. } \\
\text { Dev. }\end{array}$ & 1 & 2 & 3 & 4 & 5 & 6 & 7 & 8 & 9 & 10 & 11 \\
\hline 1. Goal Reached & 0.31 & 0.46 & 1 & & & & & & & & & & \\
\hline 2. Log of Goal Amount & 8.57 & 1.29 & $-.438 * *$ & 1 & & & & & & & & & \\
\hline 3. Fixed or Flexible & 0.97 & 0.16 & $-.144 * *$ & 0.008 & 1 & & & & & & & & \\
\hline 4. Team Members & 1.77 & 2.62 & 0.008 & $.148^{* *}$ & 0.011 & 1 & & & & & & & \\
\hline 5. Website & 0.54 & 0.50 & $-.021 * *$ & $.150 * *$ & $-.025^{* *}$ & $.116^{* *}$ & 1 & & & & & & \\
\hline 6. Entrepreneurial & 0.09 & 0.28 & $-.048 * *$ & $.105^{* *}$ & $-.081 * *$ & $-.026 * *$ & $.074 * *$ & 1 & & & & & \\
\hline 7. Creative & 0.65 & 0.48 & $.031 * *$ & $-.063 * *$ & $.028 * *$ & $.093 * *$ & $.073^{* *}$ & $-.418 * *$ & 1 & & & & \\
\hline 8. Reward Offered & 0.82 & 0.38 & $.029 * *$ & -0.008 & $.037 * *$ & $.127 * *$ & $.230 * *$ & $-.024 * *$ & $.336^{* *}$ & 1 & & & \\
\hline 9. Reward Levels & 5.54 & 3.61 & $-.021 * *$ & $.177^{* *}$ & 0.002 & $.209^{* *}$ & $.275^{* *}$ & 0.00486 & $.352 * *$ & $.717 * *$ & 1 & & \\
\hline 10. Updates & 4.43 & 8.23 & $.054 * *$ & $.090 * *$ & $-.019 * *$ & $.196^{* *}$ & $.117^{* *}$ & 0.00048 & $.058 * *$ & $.103 * *$ & $.201 * *$ & 1 & \\
\hline 11. Facebook Account & 0.61 & 0.49 & $-.037^{* *}$ & $.141 * *$ & -0.009 & $.147 * *$ & $.513^{* *}$ & $.041 * *$ & $.094 * *$ & $.225 * *$ & $.294 * *$ & $137 * *$ & 1 \\
\hline
\end{tabular}

Key: $* *=$ Correlation is significant at the 0.01 level (2-tailed). 


\subsection{Logistic regression: external validation}

All indiegogo projects $(N=22,548)$, predicting project funding

Variable
CONTROLS

$\log ($ Goal $)$

Fixed or Flexible

Team Members

Website

Category

Entrepreneurial

Creative

PREDICTORS

$\begin{array}{ll}\text { Reward Offered } & \# \\ \text { Reward Levels } & \# \\ \text { Updates } & \# \\ \text { Facebook Account } & \#\end{array}$

Chi-square

Chi-square change

Nagelkerke R Square

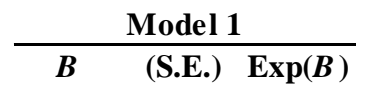

$\begin{array}{ccc}-1.15 & (0.02) & 0.32^{* * *} \\ -2.35 & (0.11) & 0.10^{* * *} \\ 0.09 & (0.01) & 1.10^{* * *} \\ 0.27 & (0.03) & 1.32^{* * *} \\ & & \\ -0.18 & (0.07) & 0.83 \\ -0.02 & (0.04) & 0.98\end{array}$

Model 3

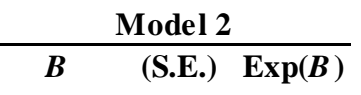

$-1.21 \quad(0.02)$

$-2.36 \quad(0.11)$

$\begin{array}{ll}-2.36 & (0.11) \\ 0.08 & (0.01)\end{array}$

$0.2043 \quad(0.04)$

$-0.29 \quad(0.07)$

$-0.20 \quad(0.04)$
$0.30^{* * *}$
$0.09^{* * *}$
$1.08^{* * *}$
1.23

$0.75^{* * *}$

$0.82^{* * *}$

$\begin{array}{ccc}-0.19 & (0.07) & 0.83^{* *} \\ 0.08 & (0.01) & 1.08^{* * *} \\ \# & & \\ \# & & \end{array}$

$-1.19$

$-2.34$

$-2.34$

0.08

0.23

(0.02)

$(0.11)$

$(0.01)$

(0.04)
$6,144.9^{* * *}$
145.7
0.336

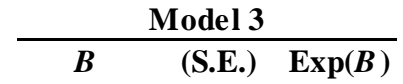

$\begin{array}{lll}-0.19 & (0.07) & 0.01 \\ -0.05 & (0.04) & 0.23\end{array}$

0.329

\begin{tabular}{ccc}
$\#$ & & \\
$\#$ & & \\
0.03 & $(0.00)$ & $0.00^{* * *}$ \\
0.01 & $(0.04)$ & 0.82 \\
\multicolumn{3}{c}{} \\
\multicolumn{3}{c}{$6,240.5^{* * *}$} \\
& 95.6 \\
& 0.341
\end{tabular}

\begin{tabular}{crr}
\multicolumn{3}{c}{ Model 4 } \\
\hline B & (S.E.) & $\operatorname{Exp(B)}$ \\
& & \\
-1.23 & $(0.02)$ & $0.29^{* * *}$ \\
-2.35 & $(0.12)$ & $0.10^{* * *}$ \\
0.07 & $(0.01)$ & $1.07^{* *}$ \\
0.20 & $(0.04)$ & $1.22^{* * *}$ \\
& & \\
-0.28 & $(0.07)$ & $0.76^{* * *}$ \\
-0.19 & $(0.04)$ & $0.83^{* *}$
\end{tabular}

** = Correlation is significant at the $<0.01$ level (2-tailed).

$* * *=$ Correlation is significant at the $<0.001$ level (2-tailed).

${ }^{1}$ Note: The supracategory for "Cause" projects is subsumed as a dummy variable in the intercept term. 


\section{APPENDIX B: SUPPLEMENTARY MATERIALS}

\subsection{Kickstarter campaign page}

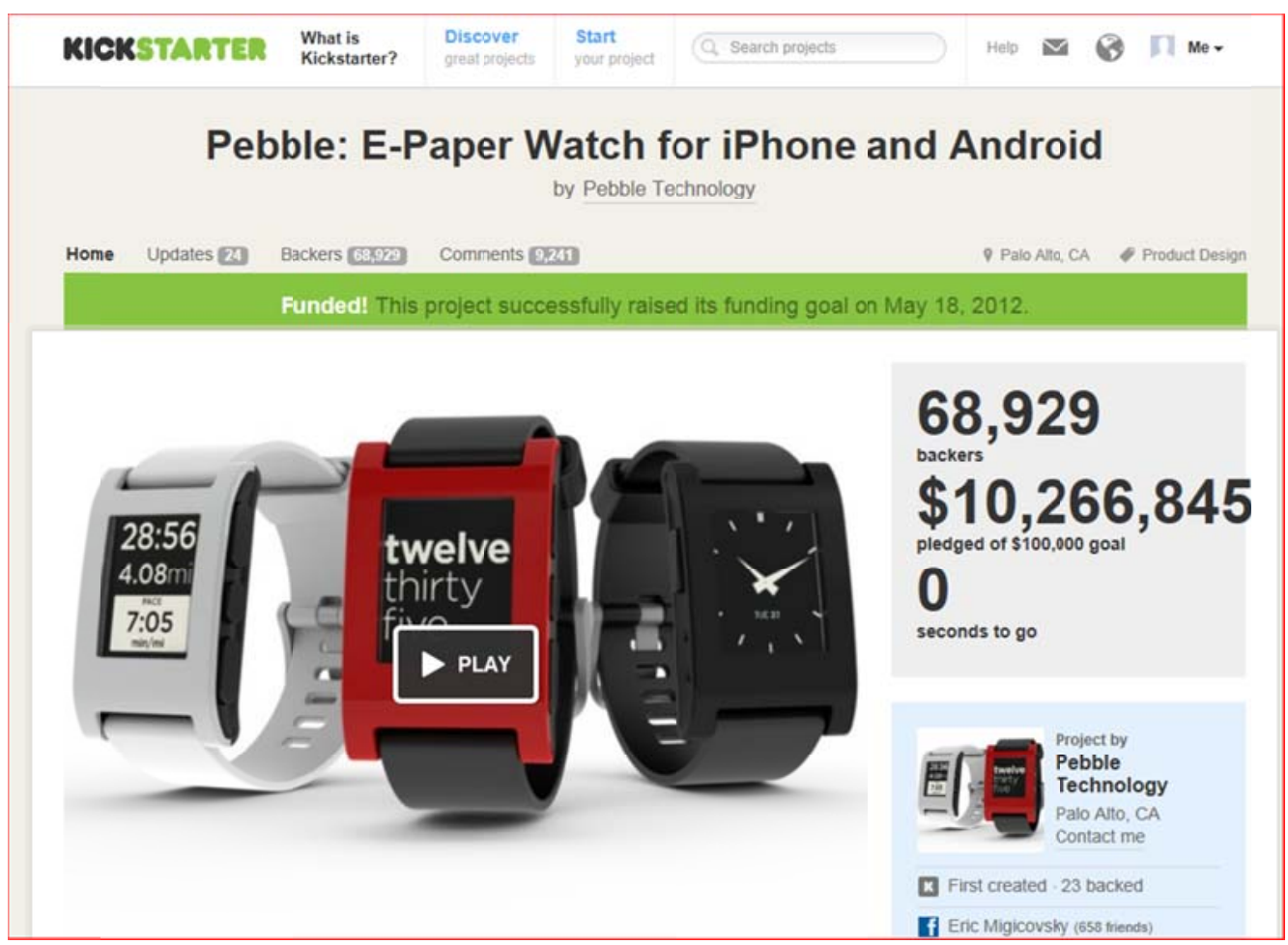




\subsection{Symbid campaign page}

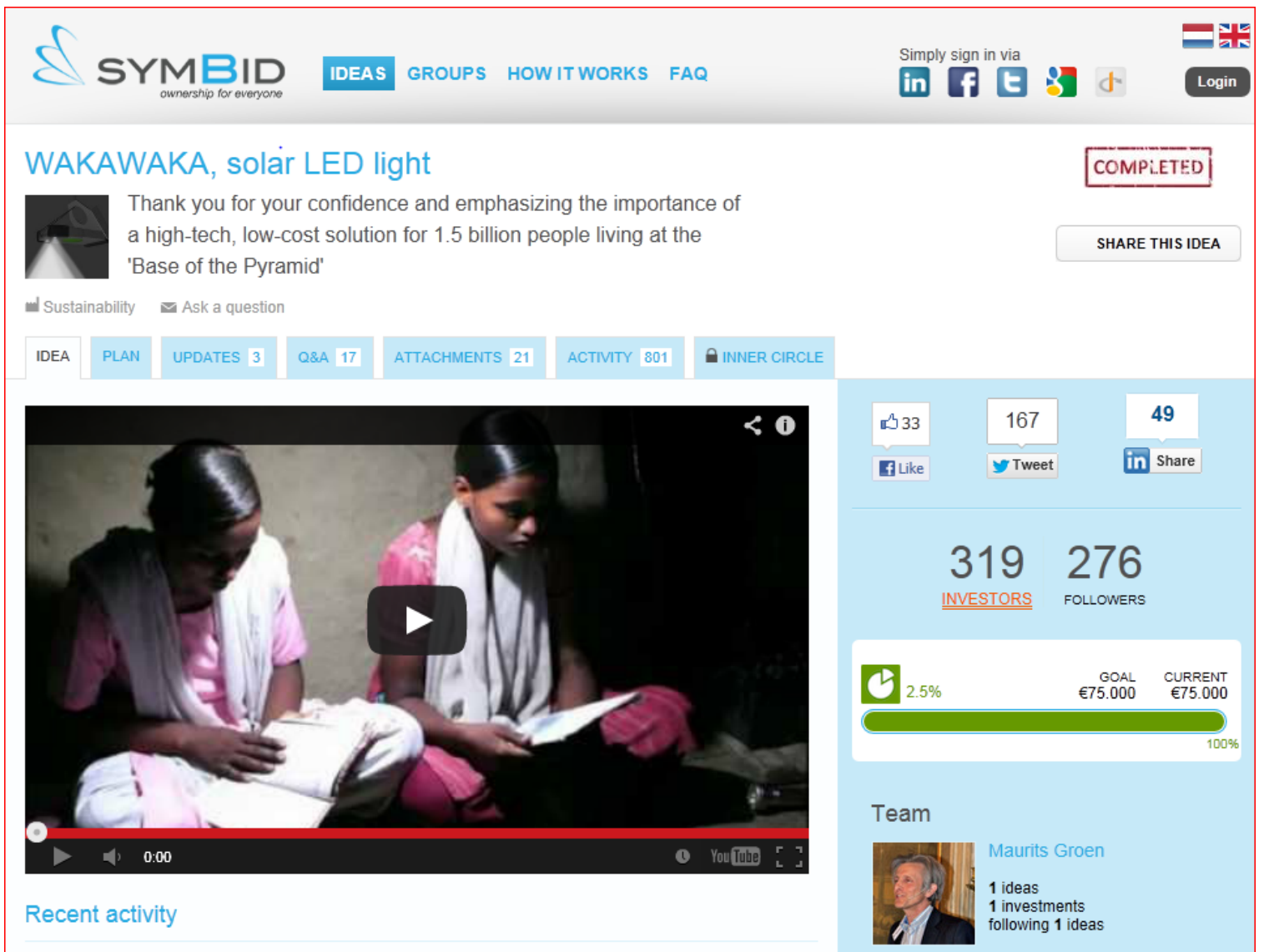




\section{3 indiegogo campaign page}
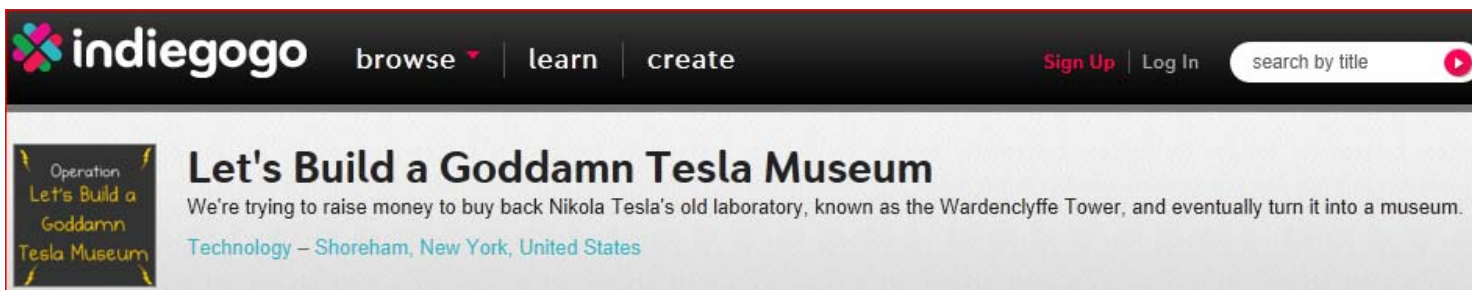

\section{Let's Build a Goddamn Tesla Museum}

We're trying to raise money to buy back Nikola Tesla's old laboratory, known as the Wardenclyffe Tower, and eventually turn it into a museum.

Technology - Shoreham, New York, United States

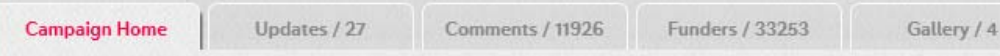

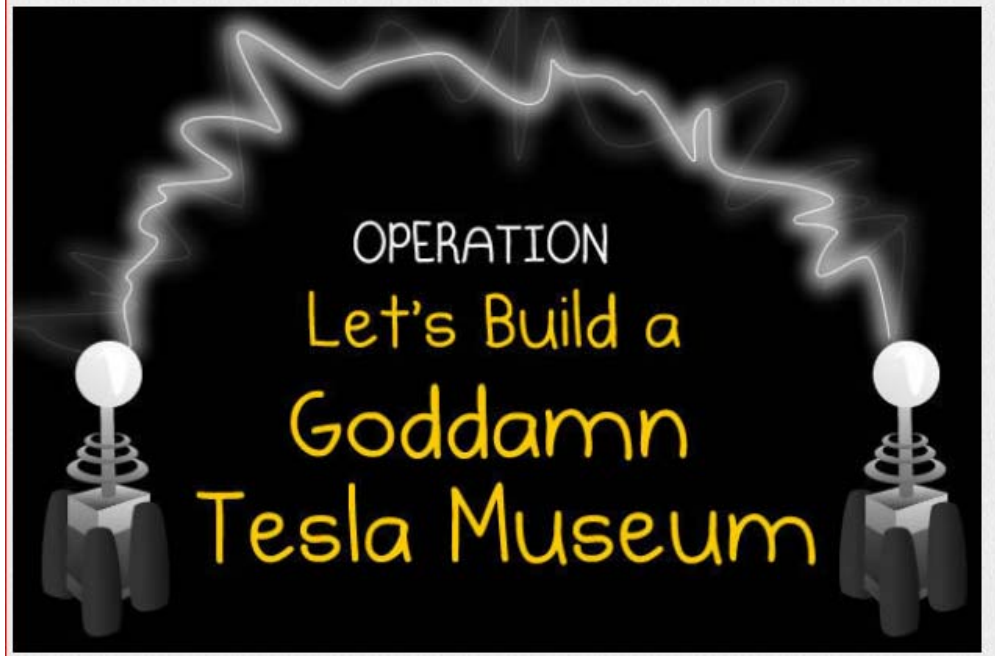

$\$ 1,370,461$

Raised of $\$ 850,000$ Goal

(b) O time left

$\Delta \Delta$ Flexible Funding campaign

This campaign received all of the funds contributed by Sat 29 Sep.

Perks for your contribution

\section{$\$ 3$}

Tesla loves the number 3 


\subsection{Kickstarter data: impact on independent film}

Data from Kickstarter regarding selected outcomes for crowdfunded films ${ }^{20}$ :

- At least 86 Kickstarter-funded films have been released theatrically, screening in more than 1,500 North American theaters according to Rentrak. Another 14 films have theatrical premieres slated for 2013.

- According to Rotten Tomatoes, three of the 20 best-reviewed films of 2012 are Kickstarter-funded. Another Kickstarter-funded film, Pariah, was among the best-reviewed of 2011 .

- Five films have been nominated for Oscars in the past two years.

- Kickstarter-funded films comprised $10 \%$ of films screened at the Sundance Film Festival in 2012 and 2013. In total, 49 Kickstarter-funded films have been official selections at the prestigious festival.

- Kickstarter-funded films comprised $10 \%$ of films screened at the 2012 SXSW Film Festival and Tribeca Film Festival. In total, 57 Kickstarter-funded films have premiered at SXSW and 21 at Tribeca.

- At least 16 Kickstarter-funded films have been picked up for national broadcast through HBO, PBS, Showtime, and other networks.

- Kickstarter-funded films have won at least 21 awards at the Sundance, SXSW, Tribeca, Cannes, and Berlinale festivals.

- Eight Kickstarter-funded films are nominated for Independent Spirit Awards (2013).

\footnotetext{
${ }^{20}$ Source: Kickstarter blog, http://www.kickstarter.com/blog/1133. Accessed 7 April 2013.
} 


\section{Appendix C: CroWdFunding OVERVIEW}

A revolution in information technology, especially with regard to Internet-enabled social media (sometimes called Web 2.0 or, even more recently, Web 3.0), has amplified the ways in which individuals and organizations establish, manage, and leverage their personal networks. Facebook and LinkedIn are among the most well-known examples of online social networking tools that enable users to connect through text messages and related media, with friends, associates, customers, suppliers, and a myriad constellation of personal and professional contacts. Given the abundance of data about relationships crated by these tools, they have also given researchers a new window through which to observe the patterns and processes of social networks in various contexts.

\subsection{Crowdfunding defined}

Crowdfunding is a method for collecting many small, individual amounts of money from large numbers of people through the Internet in order to fund projects and businesses, either in the form of a donation, a loan, or in exchange for a token reward, voting rights, or equity ownership (e.g., Belleflamme et al., 2010; Schwienbacher \& Larralde, 2012). Most crowdfunding campaigns are intermediated by online platforms (i.e., web sites) that facilitate the exchange between individuals who are seeking funding and those who are willing to provide it.

\subsection{Antecedents: crowdsourcing and microfinance}

Crowdfunding is derived from two related concepts: crowdsourcing and microfinance (Bradford, 2012). Crowdsourcing is the "outsourcing" of tasks to the 
general public on the Internet (Kleemann, Voss, \& Rieder, 2008). The particulars may vary, but often a firm or an individual may submit an open call on the Internet for contributions of time and or talent to solve a problem, generate ideas, or provide feedback. Contributors from the "crowd" may be compensated or they may choose to volunteer their time. Wikipedia is probably the widely known - and widely used crowdsourced project, in which thousands of individual contributors volunteer their time and expertise to continually add to and update entries for this online encyclopedia.

Microfinance is the other antecedent to crowdfunding. Sometimes just called micro-lending, microfinance usually refers to very small loans made to poorer borrowers or borrowers with little to no credit history. Microlending came to prominence with the emergence of the Grameen Bank in Bangladesh, under the leadership of Muhammad Yunus, both of whom were the awarded the Nobel Peace Prize in 2006. Now a multibillion-dollar industry, microfinance has numerous permutations, although generally it still functions to provide relatively small amount of funding to (often, very) small entrepreneurial ventures. Crowdfunding is the combination of crowdsourcing (i.e., based on the contributions of many) and microfinance (i.e., relatively small amounts to support entrepreneurial projects or ventures).

\subsection{Types of crowdfunding}

Today crowdfunding is an umbrella term that covers several forms of Internetenabled financing. Most crowdfunding campaigns are conducted through online 
platforms, which can be broadly categorized into the following three main types, with some variation within each type: 1) donation; 2) lending; and, 3) equity.

\section{Donation}

Pure donation-based crowdfunding platforms, in which funds are solicited as nontax-deductible donations are relatively rare, but they do exist. In fact, most Americans will be familiar with online fundraising efforts for political campaigns. During the 2008 presidential election cycle, the campaign to elect Barack Obama was especially successful raising small donations from large numbers of supporters via the Internet. Far more common than pure donations are sites that facilitate funding campaigns in which "donors" receive a reward or token gift in exchange for their financial commitment. Kickstarter.com operate on this model; campaigns run for a limited period, and project owners are required to offer their supporters a token gift (e.g., t-shirt, poster, card) or possibly something even more substantial, depending the level of support. On-air pledge drives for public radio or television are probably the most similar offline example of this process. The last variation on the donation-based model is one in which backers are promised delivery of the product that is being developed (e.g., film, audio recording, software, or other technology). A company called, "Pebble Technology" famously raised over \$10 million on Kickstarter, largely from individual "donors" who were promised delivery of its novel "e-paper" watch in exchange for their financial support. Crowdfunding campaigns like this are more akin to standard product pre-purchase efforts. For all of the donation-based variants described here, the crowdfunding platform collects a fee, usually based on a percentage of the total funds raised in the campaign. 


\section{Lending}

Crowdfunding also refers to loans solicited online from the public. So-called peerto-peer (P2P) lending, like donation- and reward-based models described above, are generally intermediated by a website that presents information about borrowers to prospective lenders. Lending rates are then determined through a bidding process, often in a reverse auction. Loans are not collateralized, and borrowers must repay the full amount of the loan with interest in a fixed amount of time. Some P2P lending sites, such as Prosper.com and LendingClub.com, operate as for-profit enterprises; however, not all of the borrowers are seeking funds for new projects or ventures. According to a 2011 report by the U.S. General Accountability Office (GAO), 25\% of borrowers on Prosper.com and 57\% on LendingClub, were using P2P lending to consolidate debt or pay off credit cards. Also, on Prosper, as many as $47 \%$ of borrowers did not indicate a loan purpose (Scire, 2011). Other P2P lending sites, such as Kiva.org, are non-profits, in which lenders essentially "donate" interest earned on each loan, which is then used to provide funding for agencies that monitor the use of the funds by entrepreneurs.

\section{Equity}

The most recent development in crowdfunding is the use of online platforms to solicit funding from the public in exchange for partial equity ownership in an entrepreneurial venture. Equity-based crowdfunding platforms have been operating in certain countries for about the past ten years, depending on the regulatory restriction on public solicitations for equity. This method of fundraising has been relatively uncommon in the United States since the Securities and Exchange Commission (SEC) imposed 
numerous restrictions on public raises. However, with the passage of the "Jumpstart Our Business Startups" (JOBS) Act was passed by both houses of Congress and signed into law by President Obama in April 2012, equity-based crowdfunding has now been made permissible in the United States, subject to certain conditions. The SEC has yet to complete its rulemaking process, but it is expected that equity crowdfunding will be available to any new venture through an approved crowdfunding portal by sometime in 2013. As a result, there has been heightened interest in this emergent model, and equity crowdfunding platforms in other countries have already begin to demonstrate the potential of this capital creation mechanism, especially for new ventures.

\subsection{Scale and scope}

Complete and accurate data regarding the full scale and scope of crowdfunding is not yet available. One report, based on surveys of crowdfunding website operators, estimates that there are roughly 450 crowdfunding platforms (CFPs) worldwide, predicting that this figure will grow to over 530 CFPs by the end of 2012 (Crowdsourcing, 2012). Furthermore, it estimates that more than US\$1.5 billion was raised globally on CFPs in 2011 through more than 1 million successful campaigns. According to the report, most CFPs are located in North America and Central Europe; outside the US, the reward-based model is largest segment (47\% of all CFPs in Europe and $68 \%$ of all CFPs in the rest of the world. In the U.S., donations-based platforms comprise the largest segment (46\%), and the equity-based models are fastest-growing segment worldwide. 